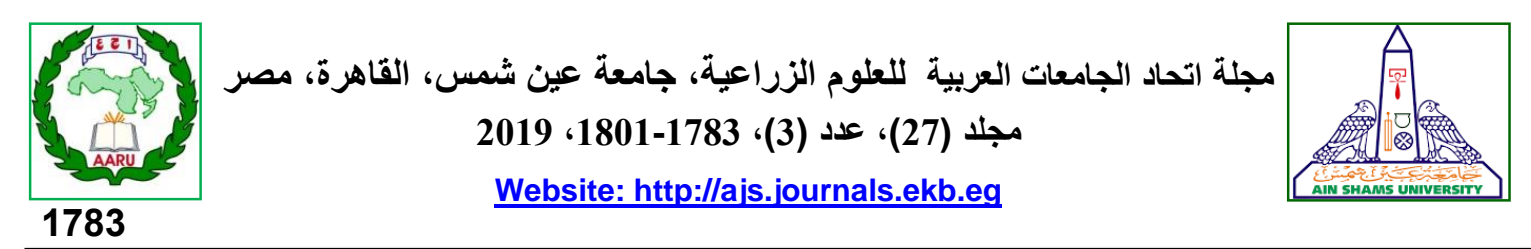

لدراسة لجاهزية استخدام وسائل التواصل الاجتماعي في الإرشاد الزراعي بمحافظة أسيوط

$$
\text { قسم المجتمع الريفي والإرشاد الزراعي - كلية الزراعد - جحمد معبد الغني" أسيوط - أسيوط - مصر }
$$

[143]

*Corresponding author: abdelghany18@aun.edu.eg

Received 26 May, 2019 Accepted 19 September, 2019

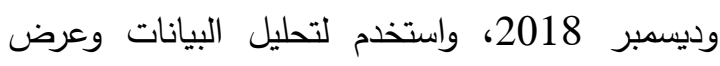

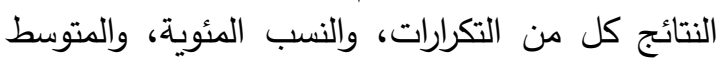

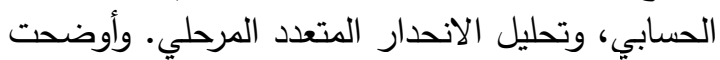

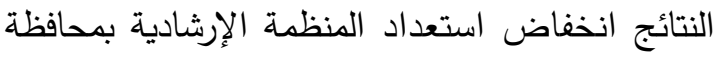

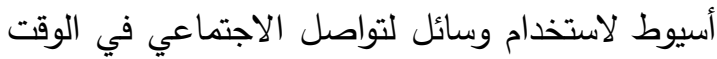
الراهن من وجهة نظر العاملين بالجهاز الإرشادي

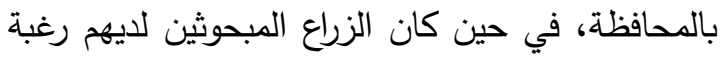

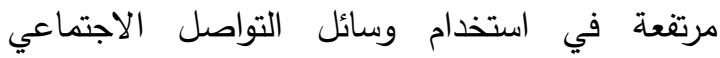

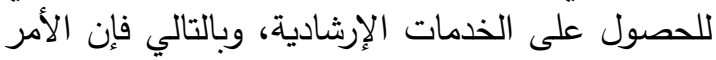

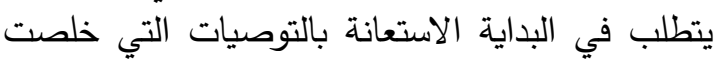

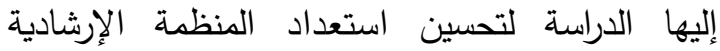

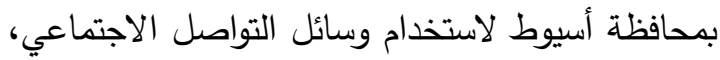
وذلك حتى يمكن استغلال رغبة الزراع المرتفعة والبدء

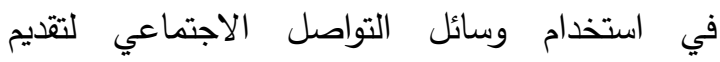
الخدمات الإرشادية بالمحافظة عن طريق تتفيذ مبادرة

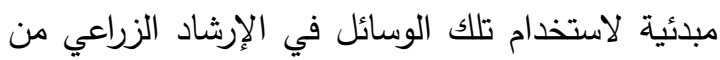
خلال الزراع المستخدمين لوسائل التواصل الإثل الاجتمادئي الزياعي

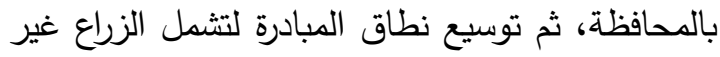

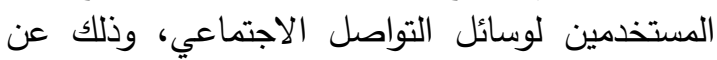

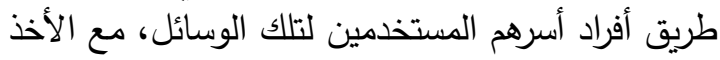

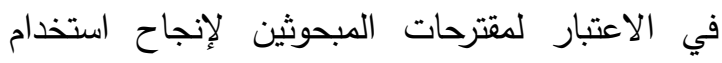

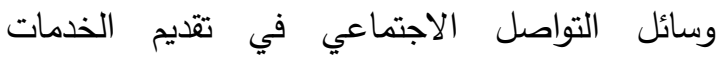

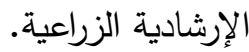

الكلمات الدالة: الجاهزية، وسائل التواصل الاجتماعى،

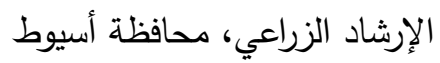

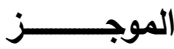

يهدف البحث الحالي بثكل عام إلى دراسة جاهزية

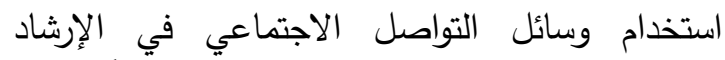
الزراعي بمحافظة أسيوط، وبشكل أكثر تحديداً تحقيق الإنيق الأهداف التالية: (1) قياس استعداد المنظمة الإرشادية

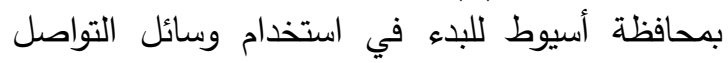

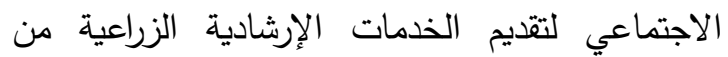

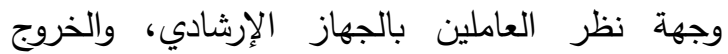

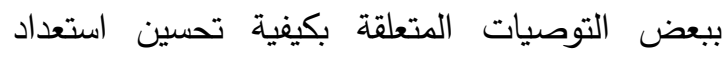

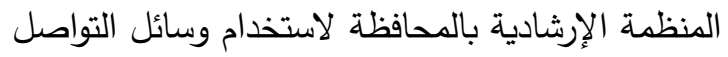

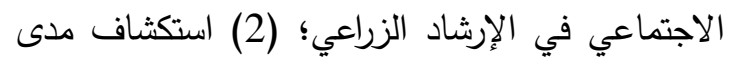
رغبة الزراع ببعض قرى محافظة أسيوط في استخدام

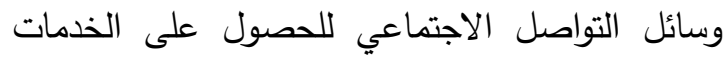

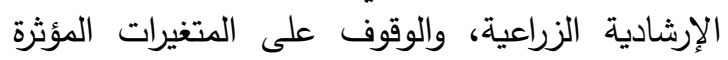

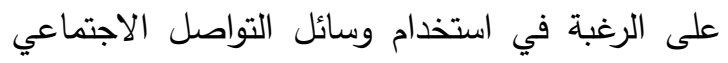

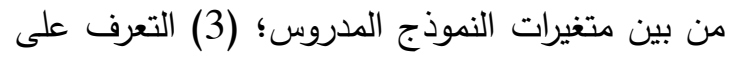
آراء المبحوثين حول مزايا ومعوقات ومقترحين المبات استخدام

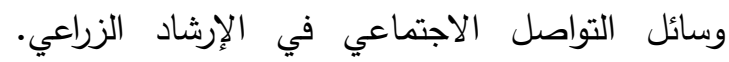

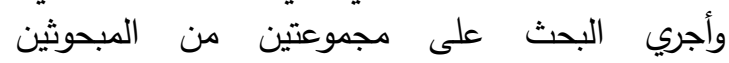
المستخدمين لواحدة على الأقل من وسائل التوبن من التواصل

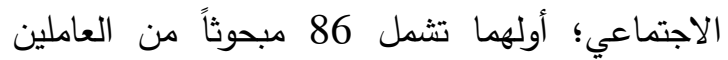
بالجهاز الإرشادي بمحافظة أسيوط، وثانيهما عينة من الإنا 120 مزارعاً تم اختيارها من أربع قرى اختيرت الرئ عشوائياً

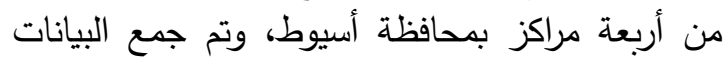

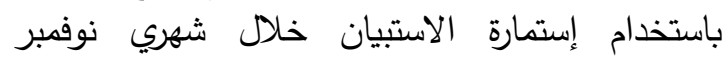


المزارعين والمرشدين، فالمعلومات المقدمة عن طريق

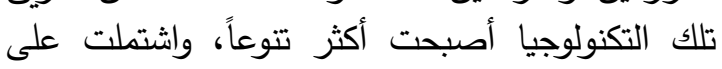

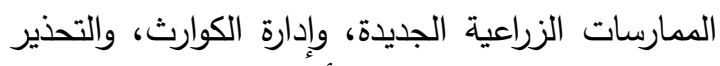

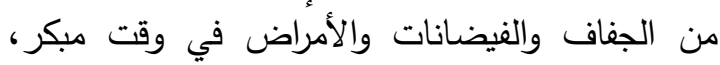

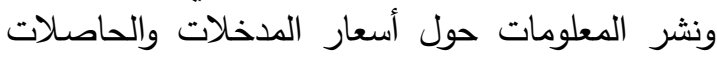

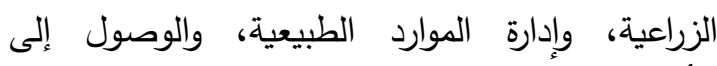

الأسواق (The World Bank, 2017). وفي هذا السياق، فقد أصبحت وسائل التواصل الاجتماعي "Social Media" ظاهرة ثقافية سائدة ذات

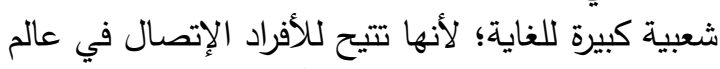
الإنترنت، وتمكن من تبادل الأفكار والمعلومات لإنيات دون

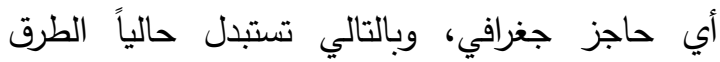

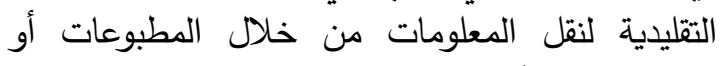

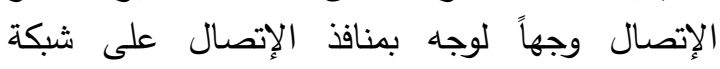

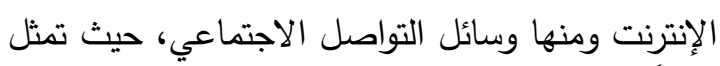

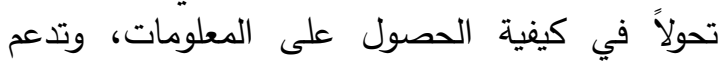

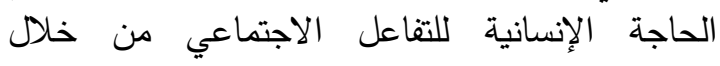

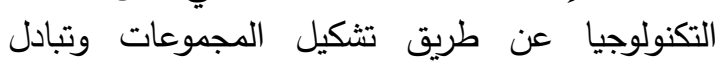
(Sokoya et al المعلومات وتوفير التواصل واتئل .2012) وهناك عدة مبررات لاستخدام وسائل التواصل

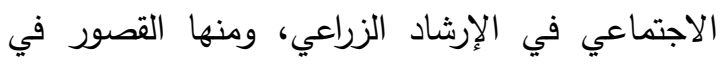

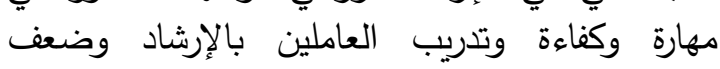

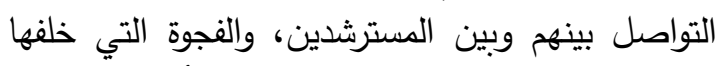

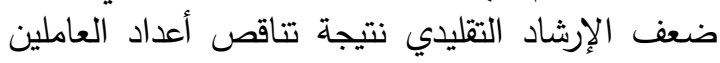
بالإرشاد في مقابل أعداد المسترشدين ونقص الإنساد التمويل

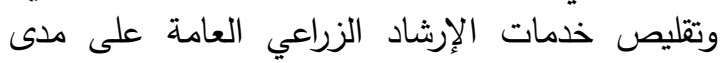

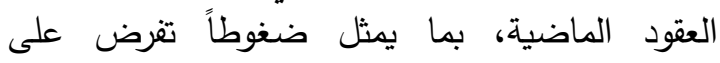

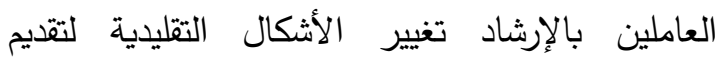
الخدمات الإرشادية ونقل التكنولوجيا من الإنصال الإنسال وجهاً لوجه إلى تللك النماذج من الإنصاد الإنكال المعتمدة على الإنى

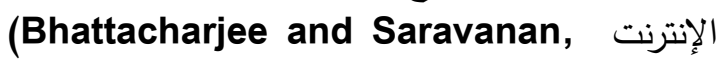
.2016)

ويعتبر التعرف على مدى الجاهزية لاستخدام أدوات

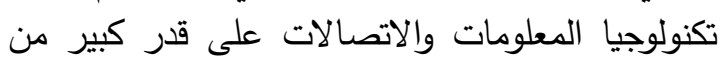

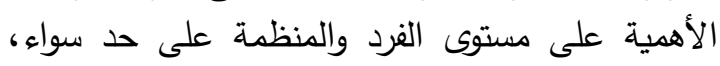
وذلك قبل البدء في أي مبادرة لتطبيق تلك التكني التكولوجيا.

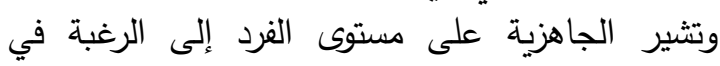

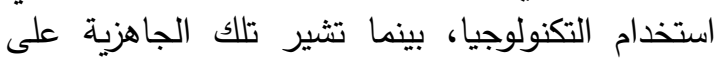

\section{المقدمة}

يواجه قطاع الزراعة في جميع أنحاء البلدان النامية

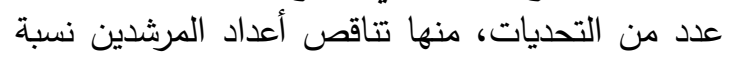

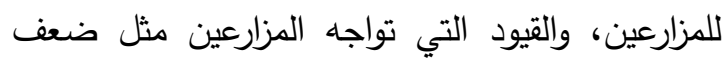

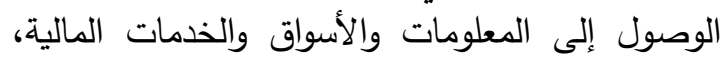

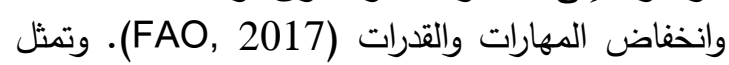
تكنولوجيا المعلومات والاتصالات أحد الحلول لتلكاتك

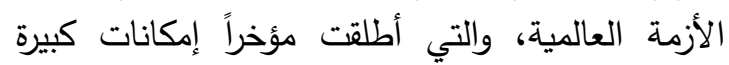
لتحسين الزراعة في التبلدان النامية على وجه التهان التحديد.

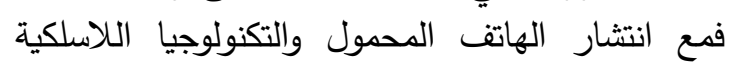

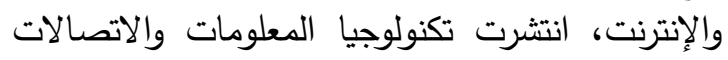

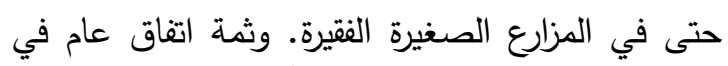

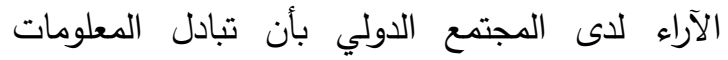

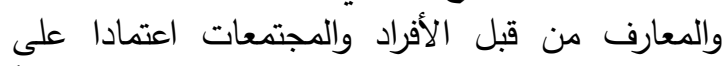
تكنولوجيا المعلومات والاتصالات الجديدة سيلعب دوراً جوهرياً في تحقيق التمية الزراعية المستدامة والأمن الغذائي (The World Bank, 2017). وتثير الإحصائيات إلى أنه في عام 2018، كانت

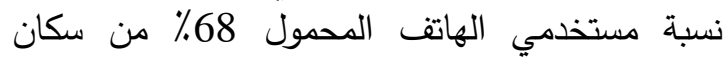

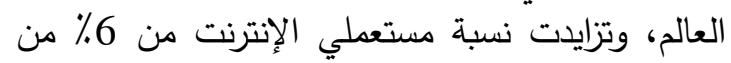

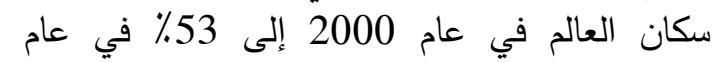

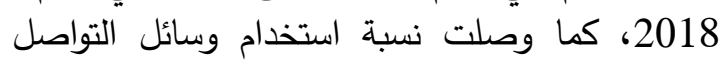

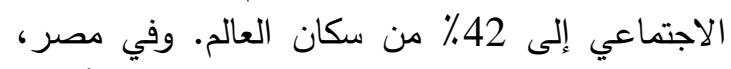

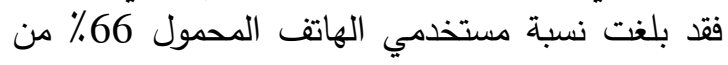

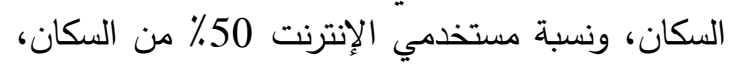

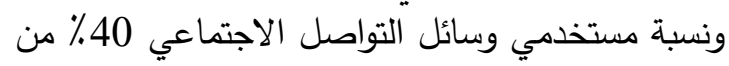
(We Are Social LTD, السكان عام 2018 .2018) هذا التغلغل المتزايد لتكنولوجيا المعلومات والاتصالات يمثل فرصة لاستخدامها في شتى مناحي التئي

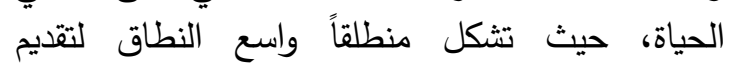
الخدمات بطريقة مبتكرة وسريعة وفعالة، وصارة وليكارت التكنولوجيا الحديثة متمثلة في الحاسب الآلي والإنترني

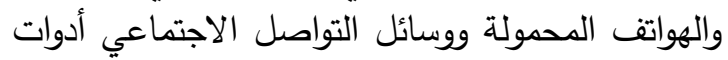

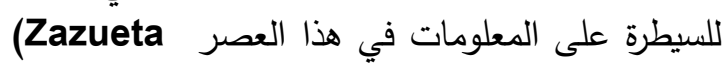
and Vergot, 2003) المعلومات والاتصالات منذ وقت طويل في تقديم

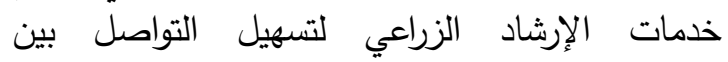


دراسة لجاهزية استخدام وسائل التواصل الاجتماعي في الإرشاد الزراعي بمحافظة أسيوط

$$
\text { 2- الإطار النظري }
$$

1-2 أهمية استخدام وسائل التواصل الاجتماعي في

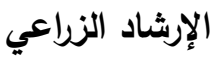

تثير وسائل التواصل الاجتماعي إلى لئى وسائل

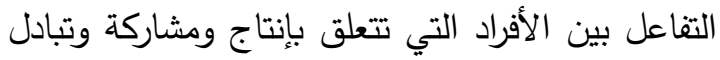

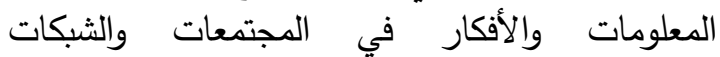
الافتراضية (Stanley, 2013)، كما تعرف بات بأنهات

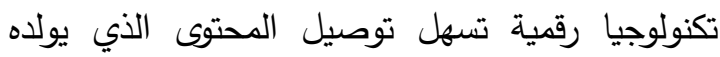
المستخدمين من خلال التفاعل المستمر ، وينظر إلى إليها أيضاً على أنها أدوات إلكترونية للاتصال عبر الإنترنت اللتبن

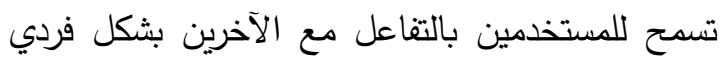

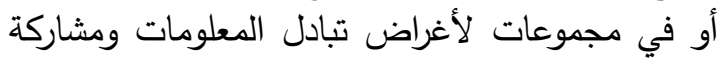

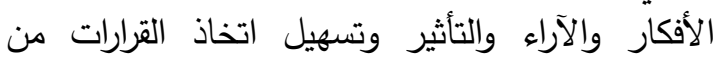

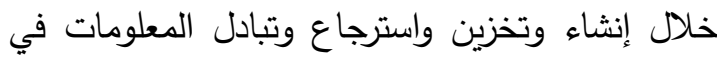
أي شكل (نصوص أو صور أو فيديو) من قبل أئي أنساء

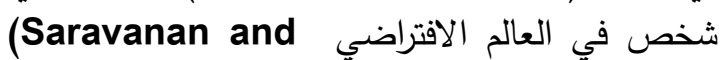
Bhattacharjee, 2017) الاجتماعي على كل من مواقع الثبكات الاجتماعية Facebook, Twitter, Instagram, Google+, )

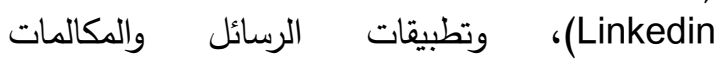
(WhatsApp, Viber) (Saravanan and (Youtube) والصور (Wha) .Bhattacharjee, 2013)

وعندما استحوذت وسائل التواصل الاجتماعي على كلى

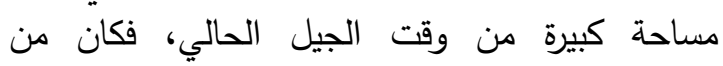
الطبيعي أن تأخذ الزراعة نصيبها من تلك المنيك المنصات

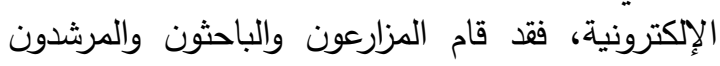

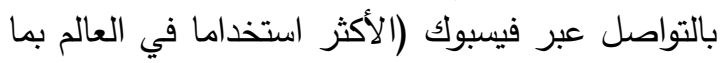
يزيد عن 1,8 مليار مستخدم نشط شهرياً على الموقع) وتويتر (موقع المدونات الصغيرة الذي يستخدمه 320 مليون مستخدم على مستوى العالم) لمشاركة آرائهر وتجاربهم وأفكارهم من خلان ملاعل جماعات مختلفة عبر آلرائر
مستوى المنظمة إلى استعداد المنظمة للاستخدام

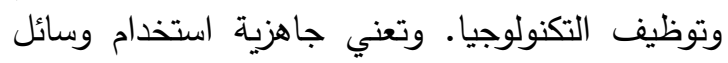

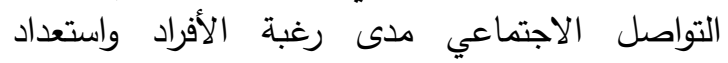
المنظمة لاستخدام وسائل التواصل الاجتماعي لأغراض ولتص مهنية معينة (Hoffmann et al 2013). وبناءً على العرض السابق، يتضح أن استخدام وسائل التواصل الاجتماعي في الإرشاد الزراعي يمثل لتراحل

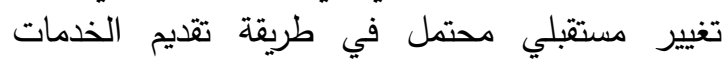

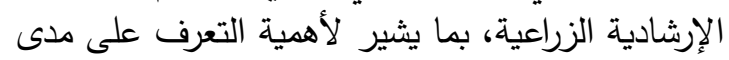

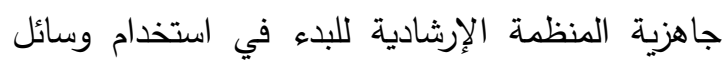

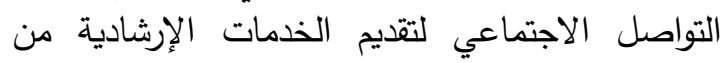
ناحية، ورغبة المسترشدين في استخدام وسائل التواصل الاصني

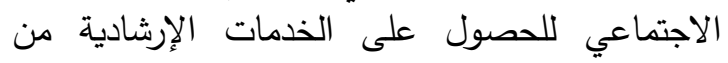

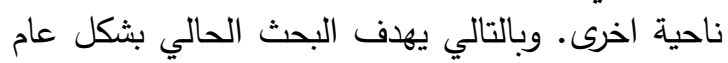

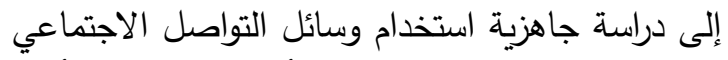

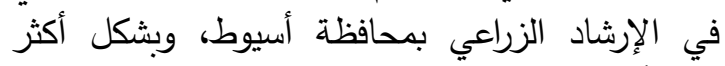
تحديداً تحقيق الأهداف التألية:

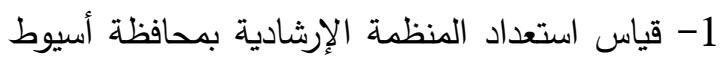

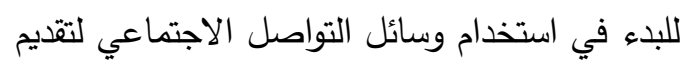

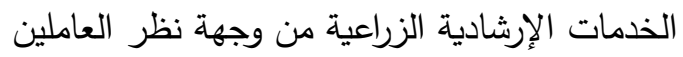

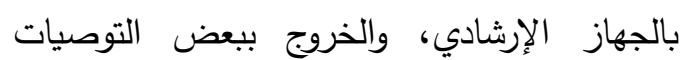

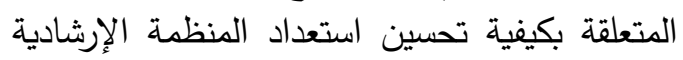

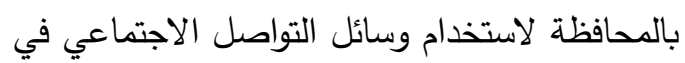
الإرشاد الزراعي. 2- استكثاف مدى رغبة الزراع ببعض قرى محافظة أسيوط في استخدام وسائل التواصل البطن الاجتماعي

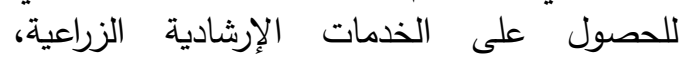

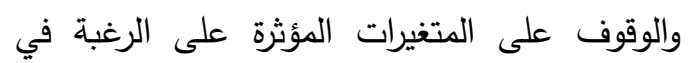

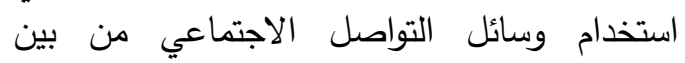
متغيرات النموذج المدروس. 3- التعرف على آراء المبحوثين حول مزايا ومعوقات الندودئ

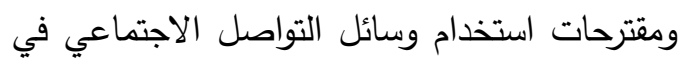

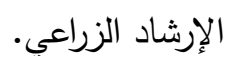


(9) تتيح فرص أكبر للعاملين بالإرشاد لتحسين أداء

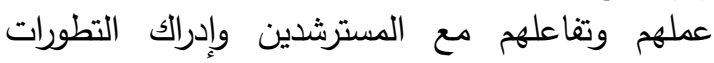
المستمرة في قطاع الزراعة بما يساهم في التطوير التطائ

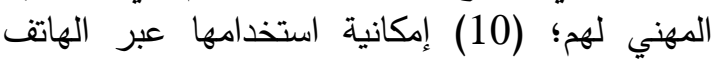

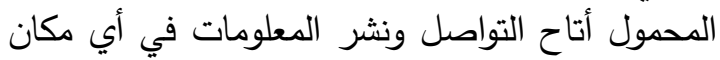

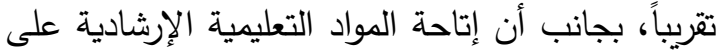

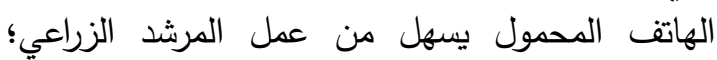

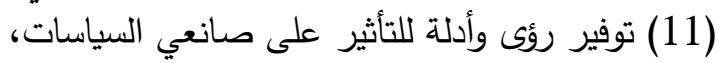

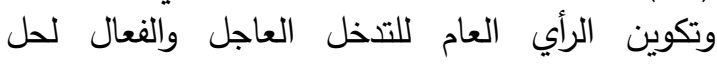
مشكلات المزارعين؛ (12) زيادة إدماج الفئات المهمشة الفئة

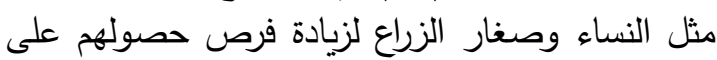

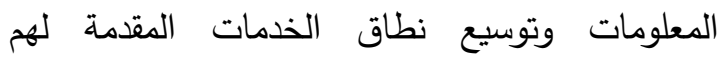
(Cornelisse et al 2011; Gharis et al 2014; Saravanan and Bhattacharjee, .2017; Thakur and Chander, 2018)

2-2 الاستعداد لاستخدام وسائل التواصل الاجتماعي

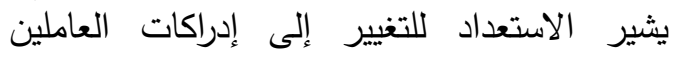

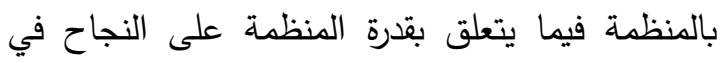

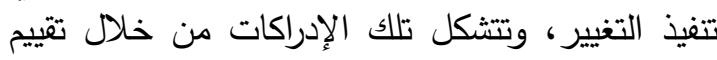

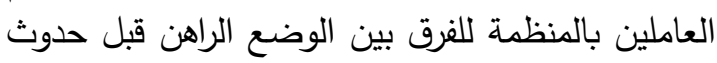

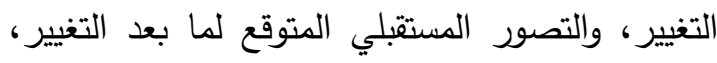

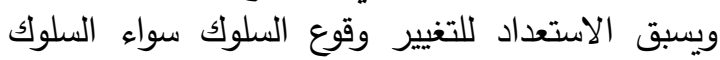
الداعم أو المقاوم للتغيير (Armenakis et al .1993; Bernerth, 2004)

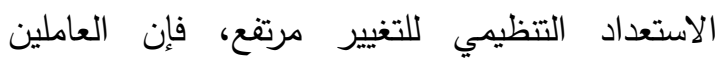

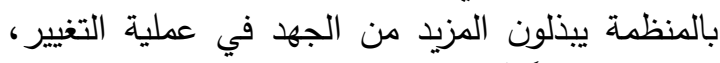

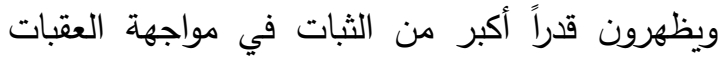

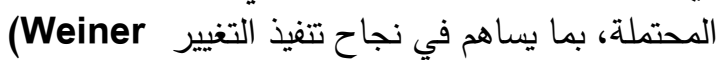

.et al 2008)

ويمكن للمنظمات المختلفة الإستفادة من وسائل

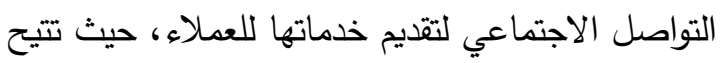
التفاعل مع الآخرين ومشاركة المحتوى الإتصالي لإني وعرض الصور والأفلام ومعرفة الأحداث، بما يجعلهات الإنها

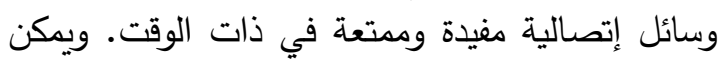

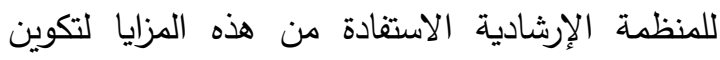

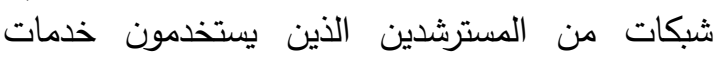

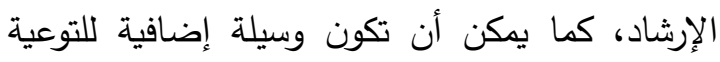
لضمان الوصول إلى أكبر عدد ممكن من المسترشدين.
فيسبوك ومواضيع شائعة على تويتر، ويسمح Youtube من خلاله مشاهدة حوالي 3,25 مليار مقطع فيديو كل فئل شهر، وأكثر من نصف من المشاهدات تتم من خلال

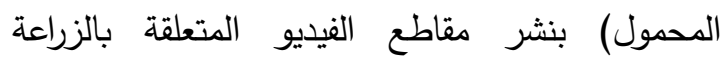

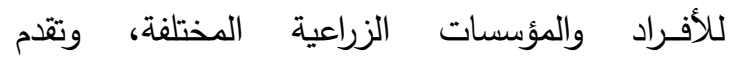
تطبيقات WhatsApp, Viber النصوص والصوت والفيديو للهواتف المحمولة،

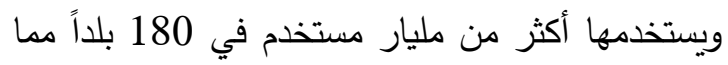
يجعلها الأكثر شعبية بين الزراع والثرشدين لتباد منادل

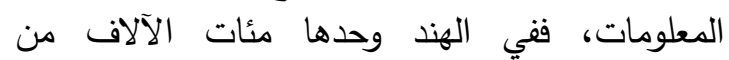
المجموعات التي تم إنثاؤها لأغراض الإرشاد الزبات الزاعي

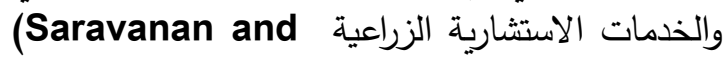
.Bhattacharjee, 2017) ويمكن للإرشاد الزراعي الاستفادة من وسائل التواصل الاجتماعي، حيث أنها تشمل مجموعة متتوعة الإنادي

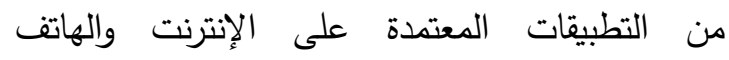

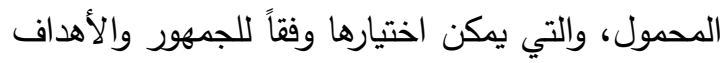

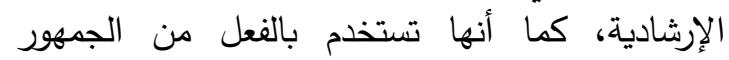
الإرشادي في التعرف على الأخبار والتسوق والتواصل التهل التهل

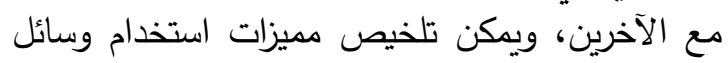
التواصل الاجتماعي في العمل الإششادي فيكن فيما يلي:

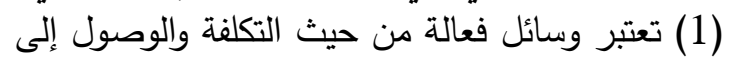

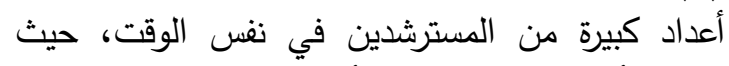

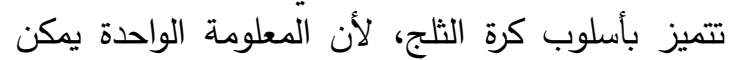

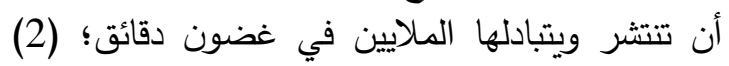

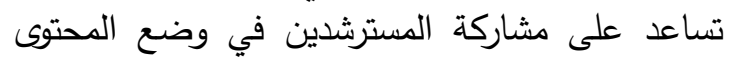

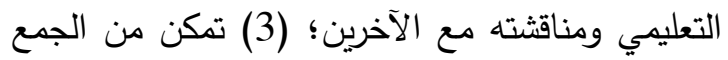

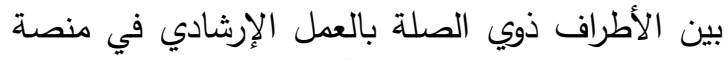

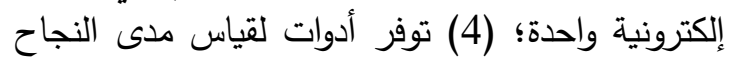
المتحقق من خلال تتبع عدد الزائرين والئرئ والأصدقاء

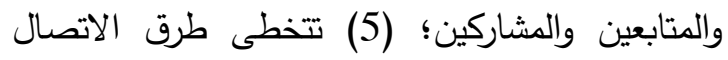

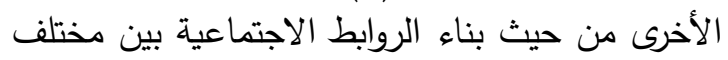

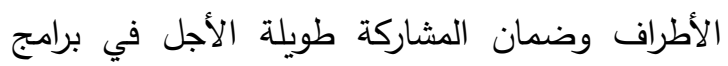

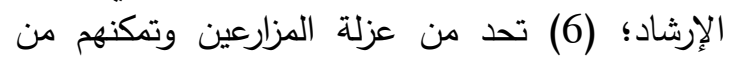

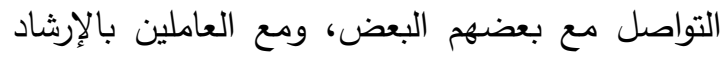

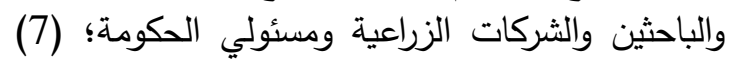

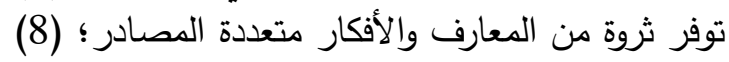
تعتبر آداه تسويقية ناجحة للمنتجات الزراعية المختلفة؛ 


\section{دراسة لجاهزية استخدام وسائل التواصل الاجتماعي في الإرشاد الزراعي بمحافظة أسيوط}

لسلوك معين يتحدد من خلال رغبته في تتفيذ هذا السلوك، والتي تتحدد بمتغيرين وهما الفائدة المدركة

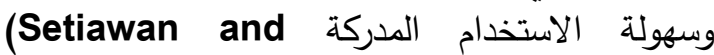
Setyohadi, 2018; Dixit and Prakash, (2018)

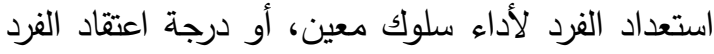

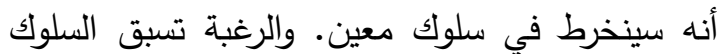

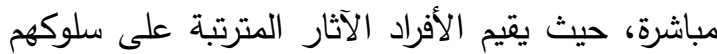

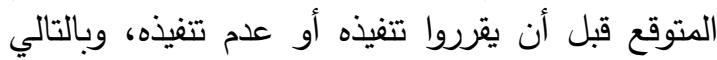
فإن الدرجة المرتفعة للرغبة تعني إحتمالية القيام (Amin and Li, 2013; Berry, بالسلوك .2017)

وعلى الرغم من أهمية نموذج قبول التكنولوجيا في

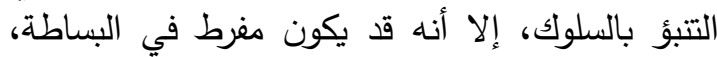
ويغفل بعض المتغيرات الهامة للتنبؤ بالرغبة في القيام بالسلوك (Venkatesh and Davis, 2000). وبالتالي فقد تم تعديل نموذج قبول التكنولوجيا عدة

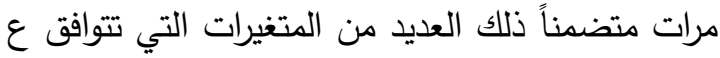
نوع التكنولوجيا المدروسة. وفي هذا الصدد، فقد قام Lopez et al (2011) التكنولوجيا لتفسير قبول تكنولوجيا وسائل التواصل

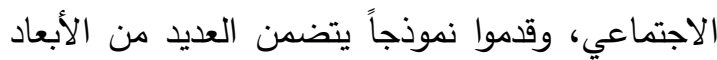
ذات الصلة بقبول وسائل التواصل الاجتماعي. ويقترح النموذج المبين في شكل (1) أن الرغبة في استخدام وسائل التواصل الاجتماعي تتأثر بالمتغيرات التالية التية:

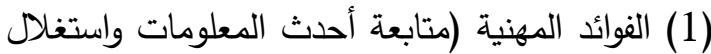
الموارد بشكل أفضل)، (2) الفوائد النفسية (المتعة والتثويق في عملية تبادل المعلومات ومشاركة الآراء)، (3) الفوائد الاجتماعية (التواصل مع الآخرين وتكوين علاقات اجتماعية جديدة)، وعيوب الاعتخدامية التها مثل: (1) التكاليف (التكاليف المادية، وغير واندان المادية مثل

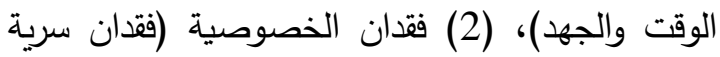

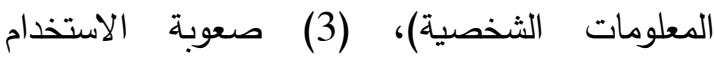
(اختلاف الآراء بين الأفراد وصعوبة البحث عن

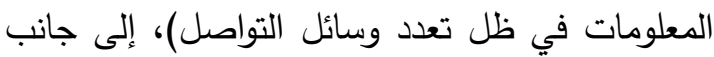

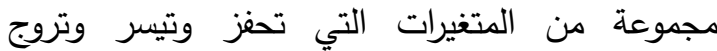

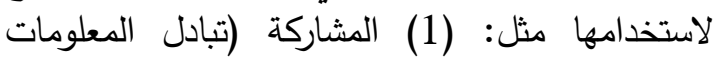
الجديدة والآراء والخبرات مع الآخرين)، (2) (إككانية الإنية الوصول (توافر الإمكانيات اللازمــة واستخـــدام الأقارب
ويعتقد البعض أن وسائل التواصل الاجتماعي تمثل فيل فال

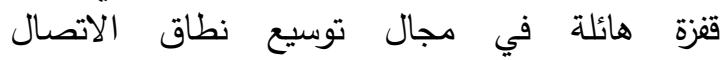
بالمسترشدين، حيث يجب أن تتميز الخدمات الإرشادية

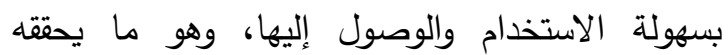
التحول إلى الإششاد عبر وسائل التواصل الاجتماعي .(Fuess, 2011)

ويعتبر مقياس استعداد المنظمة لاستخدام وسائل

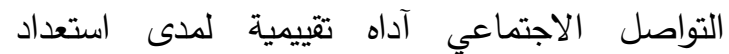
المنظمات لاستخدام وسائل التواصل التئل الاجتماعي في لداعي

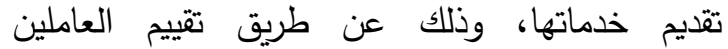
بالمنظمة للأبعاد التالية: التزام الإدارة نحو الاستيفادة من

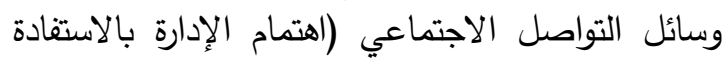

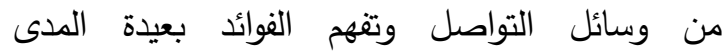
والاستعداد لتوفير الإمكانيات اللازمة)، والمعرفة بوسائل التئل

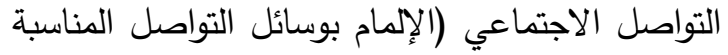

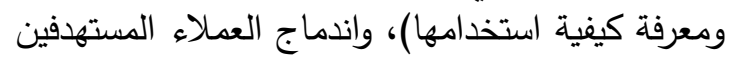
عبر وسائل التواصل الاجتماعي (وجود أعداد متزايدة

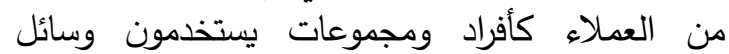

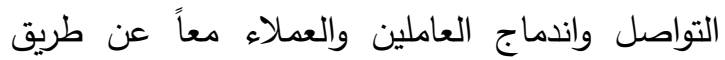
وسائل التواصل)، والنظرة التتافسية (حصر وتئييم

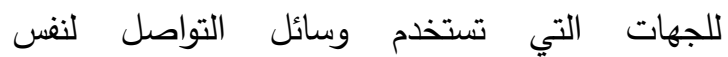
الأغراض)، وتوافر الإمكانيات المادية والبشرية (توافر لتراتئ

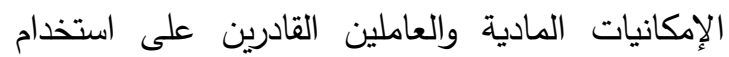

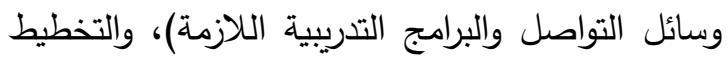

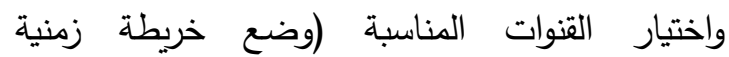
واستراتيجية طويلة المدى وتحديد القنوات المناسبة

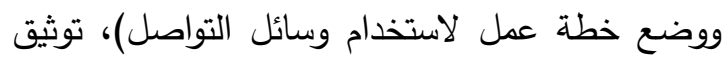

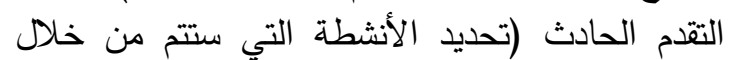

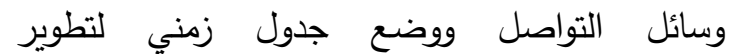
استخدامها)، والتحكم والقياس (وضع سياسة للتحكم في استخدام وسائل التواصل وتحديد طرق التقييم ووضع

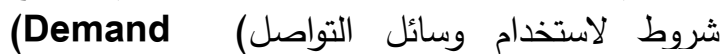
.Metric, 2009)

3-2 الرغبة في استخدام وسائل التواصل الاجتماعي يعتبر نموذج قبول التكنولوجيا (TAM) الأكثري

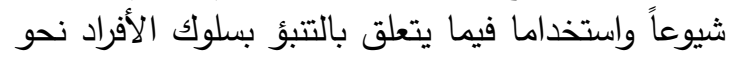

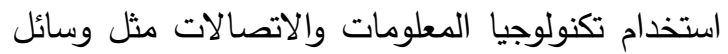
التواصل الاجتماعي، ويوضح النموذج أن أداء الفرد 


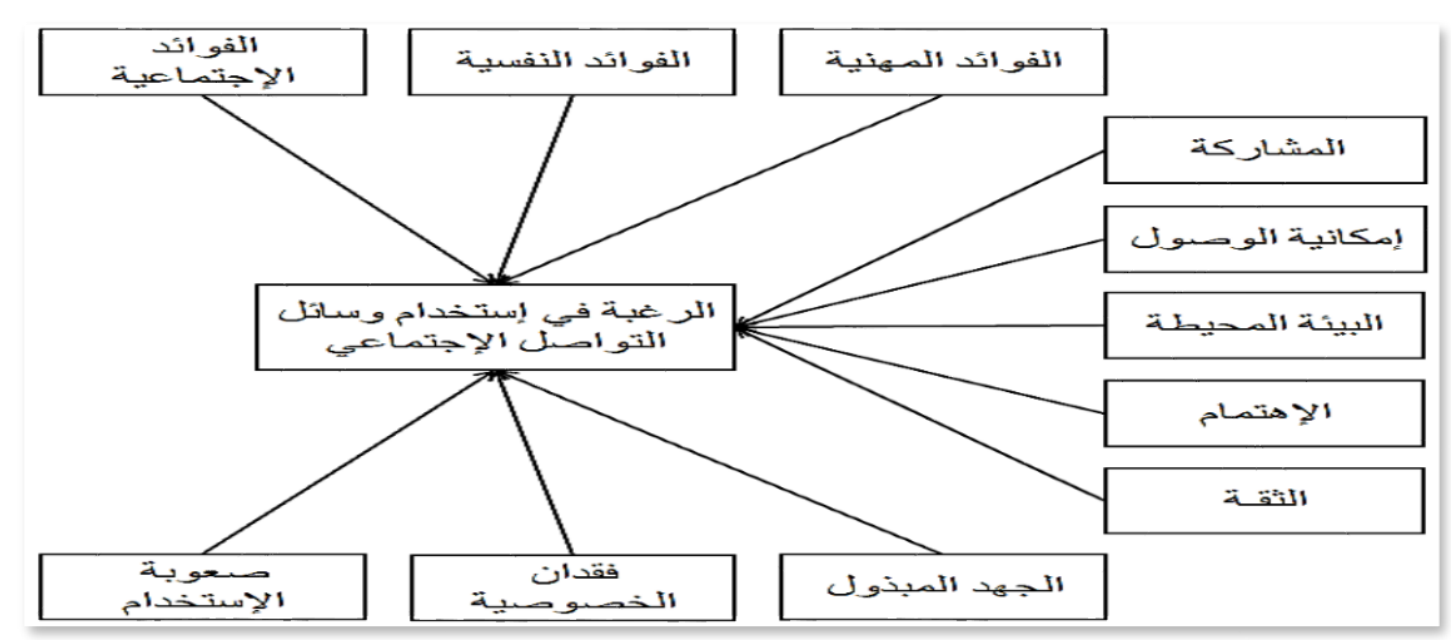

شكل 1.: نموذج الرغبة في استخدام وسائل التواصل الاجتماعي

Lopez et al 2011

الإرشادي على مقياس ليكرت خماسي الأبعاد يتراوح

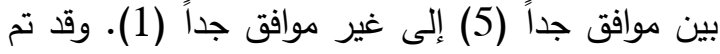

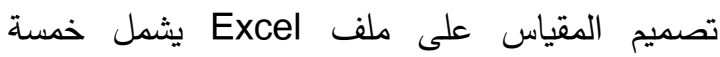
صفحات؛ تحتوي الأولى على تعليمات استخدام

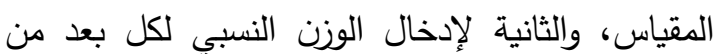

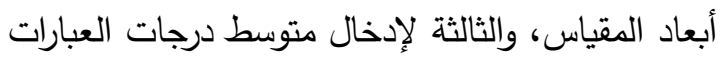

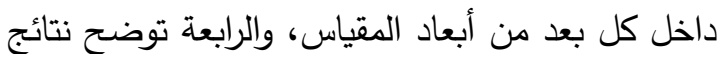

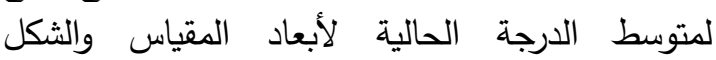
العنكبوتى الموضح لها، والأخيرة تبين التونية التوصيات المتعلقة بكيفية تحسين الاستعداد لاستخدام وسائل التواصل الاجتماعي بناء على نتائج تطبيق المقياس. كما تم استخدام نموذج الرغبة في التئي استخدام وسائل

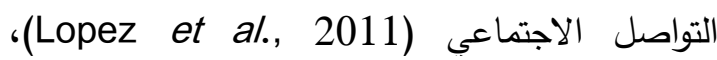
لاستكشاف مدى رغبة الزراع لقبول استخدام وسائل

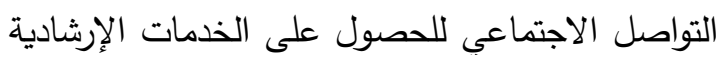

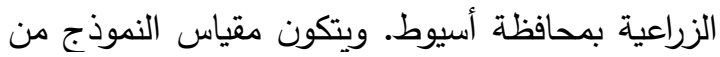

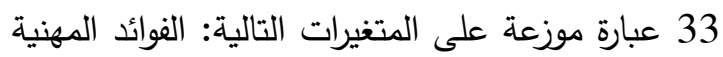

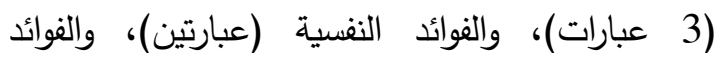

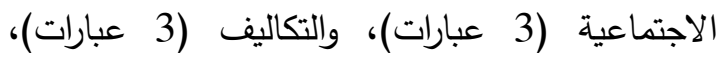

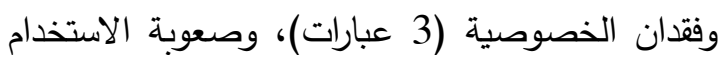

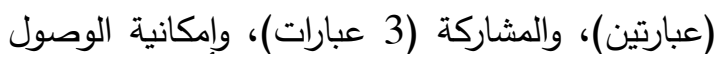
(3 عبارات)، والبيئة المحيطة (3 (3 عبارات)، والاهتئة) والهام
والجيران لتلك الوسائل)، (3) البيئة المحيطة (استخدام

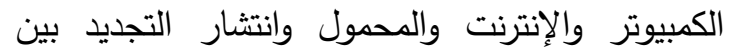

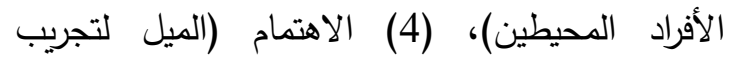
الأشياء الجديدة والمعرفة بوسائل التواصل)، (5) (5) الثقة

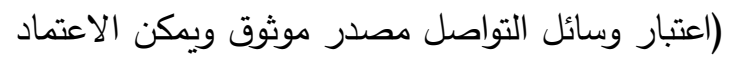
عليه). 3- طريقة إجراء البحث استخدمت الدراسة مقياس الاستعداد لاستخدام

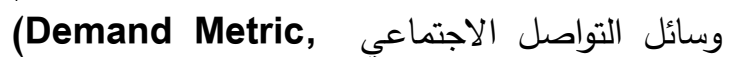
(2009 لقياس استعداد المنظمة الإرشادية للبدء في التئي

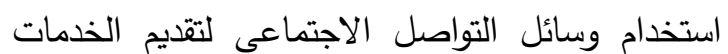
الإرشادية الزراعية بمحافظة أسيوط. ويتكون المقيتئ التياس

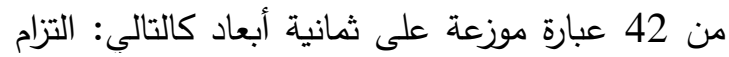

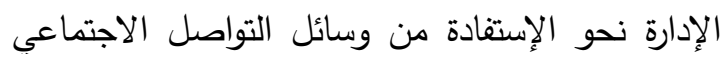

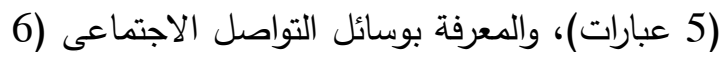

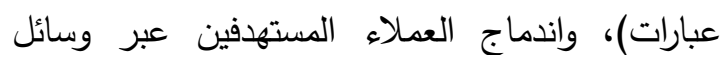

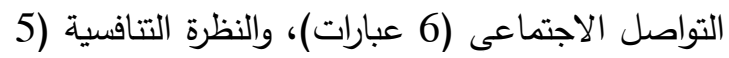

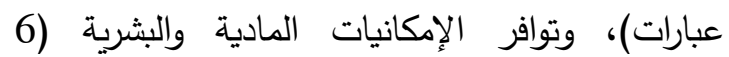

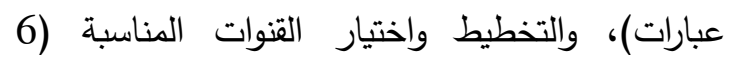

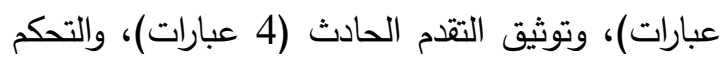
والقياس (4 عبارات). وتتدرج موافقة العاملين بالجهاز التهاري 


\section{9}

دراسة لجاهزية استخدام وسائل التواصل الاجتماعي في الإرشاد الزراعي بمحافظة أسيوط

الزراع المتاحين، ثم سأل كل منهم ليرشح آخرين

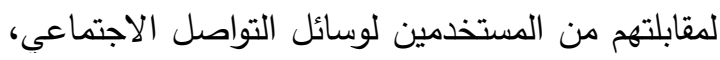

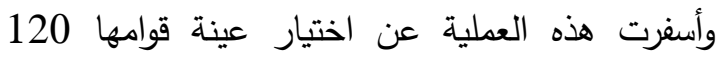

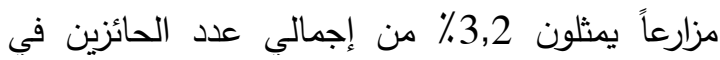
القرى المختارة والبالغ عددهم 3784 حائزاً. وقد تم جمع البيانات باستخدام إستمارة الاستبيان خلال شهري نوفمبر وديسمبر من 2018، واستخدم لتحليل

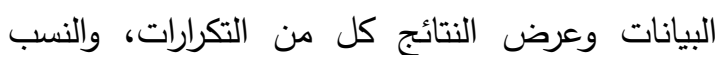

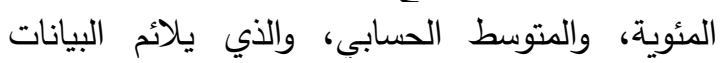

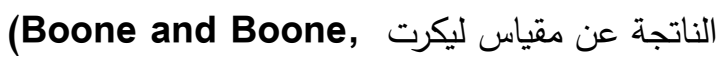
(2012، إلى جانب تحليل الانحدار المتعدد المرحلى، وتم تحليل البيانات باستخدام الحزمة الإحصائية للعلوم الإنيا

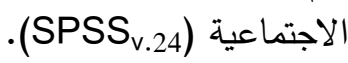

النتائـــج

أولاً: خصائص المبحوثين

1- خصائص العاملين بالجهاز الإرشادي يشير جدول (1) إلى توزيع المبحوثين من العاملين الإنين

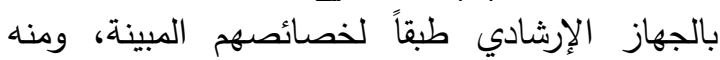
يلاحظ أن النسبة الغالبة من المبحوثين كانيانت أعمارئ العارهم

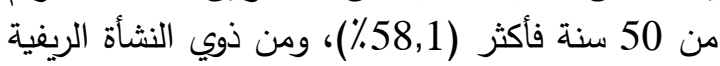

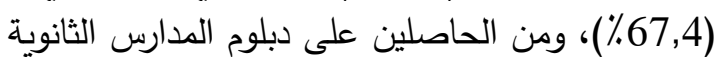

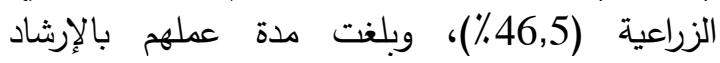

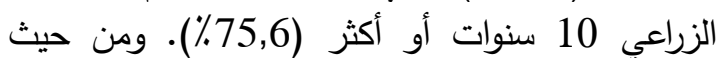
وسائل التواصل الاجتماعى التى يستخدمها العاملين الإني

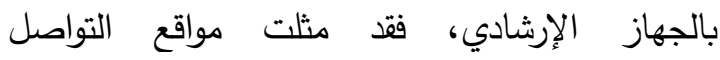

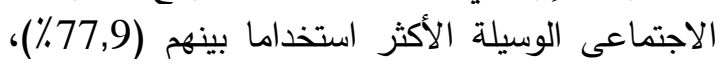

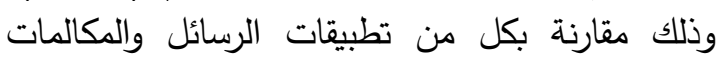
(58,1\%)، ومواقع مشاركة الفيديو (44,2\%).

2- 2- خصائص الزراع يوضح جدول (2) توزيع الزراع المبحوثين طبقاً

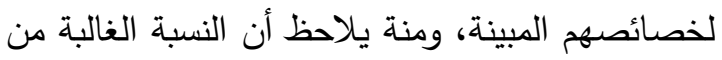
المبحوثين كانت أعمارهم أقل من 50 سنة (61,7\%)؛

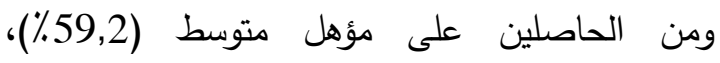

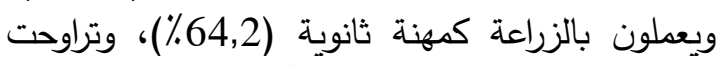

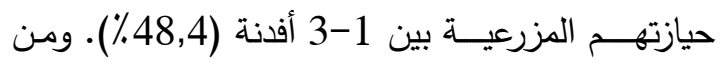

(3 عبارات)، والثقة (عبارتين)، والرغبة في الاستخدام

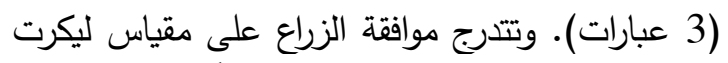
خماسي الأبعاد يتراوح بين موافق جداً (5) إلى غير لئر موافق جداً (1). وأجريت الدراسة على مجموعتين من الدبحوثين؛ حيث اشتثلت المجموعة الأولى على جميع العاملين من العين

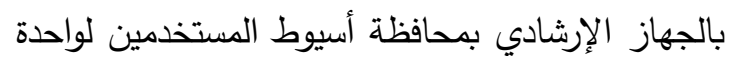

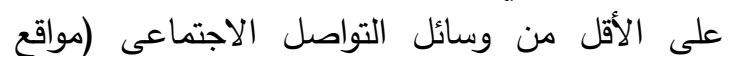
التواصل مثل فيسبوك، وتطبيقات الرسائل والمكالمات التئل

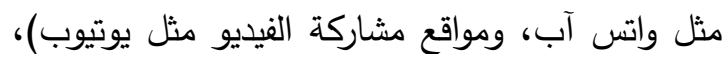
حيث تم توزيع الاستبيان على جميع العاملين بالجهاز الإرشادي بمحافظة أسيوط وعددهم 254 فرداً، وبعد التئ انتهاء عملية جمع البيانات تم استبعاد استمارات

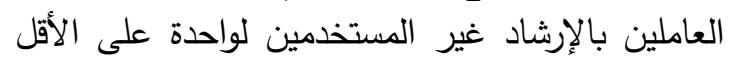

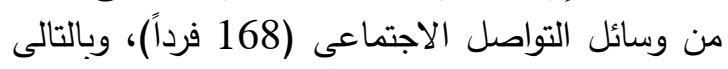

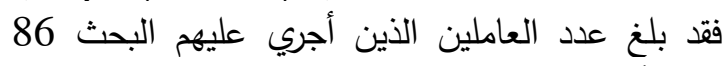
مبحوثاً يمثلون 33,9٪ من جملة العالملين بالجهاز الإرشادي بالمحافظة.

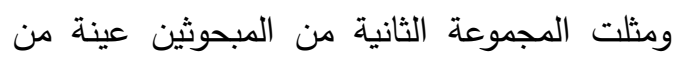

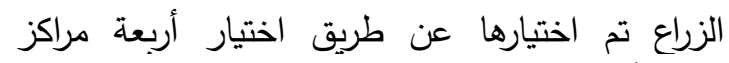

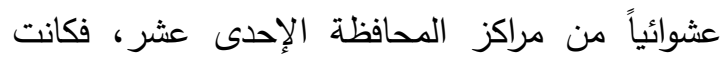
مراكز أسيوط والفتح والبداري وصدفا، ثم اختيار قرئ عثرية

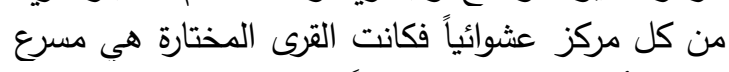

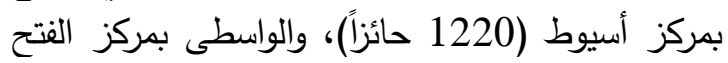

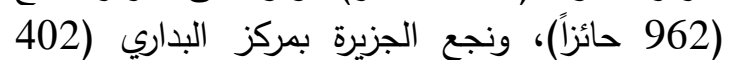
حائزاً)، وبني فيز بمركز صدفا (1200حائزاً). وحيث الجيث لا يوجد حصر بثاملة البحث الدتمثلة في الزراع الذين ونائ

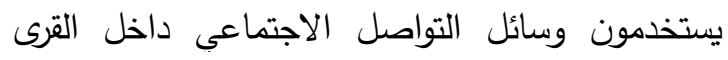
المختارة، فقد تم إتباع أسلوب المعاينة بكرة الثلتج Snowball Sampling

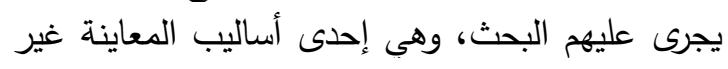
الاحتمالية التى يتم استخدامها في حالة التئ عدم توافر

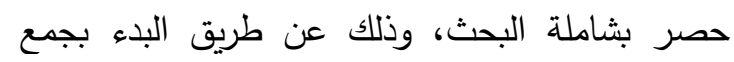

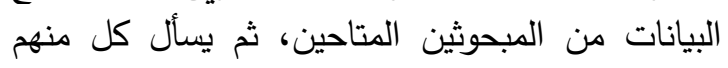

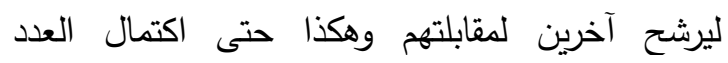

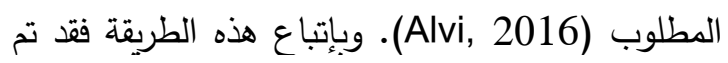

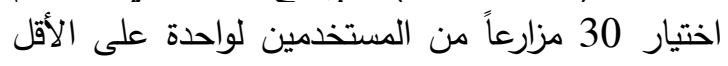
من وسائل التواصل الاجتماعي سالفة الذكر في كل التئل قرية من قرى البحث، حيث تم البدء بجمع البيانات من في 
جدول 1. توزيع المبحوثين من العاملين بالجهاز الإرشادي طبقاً لخصائصهم المبينة (ن= 86)

\begin{tabular}{|c|c|c|c|}
\hline$\%$ & العدد العد & الخصائص & p \\
\hline \multicolumn{3}{|r|}{ 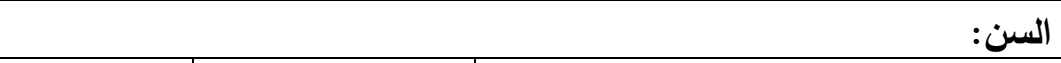 } & \multirow[t]{3}{*}{1} \\
\hline 41,9 & 36 & أقل من 50 سنة & \\
\hline 58,1 & 50 & ا 50 سنة فأكثر & \\
\hline & & | النشأة: & 2 \\
\hline 67,4 & 58 & ريفية & \\
\hline 32,6 & 28 & 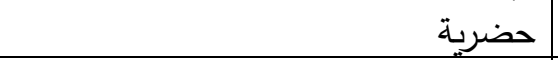 & \\
\hline & & المؤهل الدراسي: & 3 \\
\hline 46,5 & 40 & 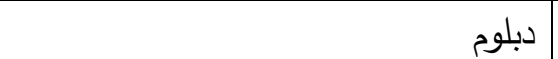 & \\
\hline 30,2 & 26 & بكالوريوس زراعة & \\
\hline 23,3 & 20 & بكالوريوس تعاون & \\
\hline & & مدة العمل بالإرشاد الزراعي: & 4 \\
\hline 24,4 & 21 & أقل من 10 سنوات & \\
\hline 75,6 & 65 & | 10 سنوات فأكثر & \\
\hline & & وسائل التواصل الاجتماعي المستخدمة: & 5 \\
\hline 77,9 & 67 & مواقع التواصل الاجتماعي (فيسبوك) & \\
\hline 58,1 & 50 & تطبيقات الرسائل والمكالمات (واتس آب) & \\
\hline 44,2 & 38 & |مواقع مشاركة الفيديو (يوتيوب) & \\
\hline
\end{tabular}

على النجاح فى تتفيذ التغيير، والتى يتم تحديدها من

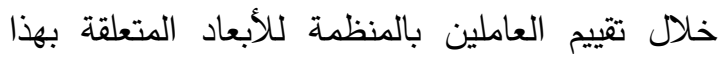
التغيير، فإن مقياس استعداد المنظمة لاستخدام وسائل

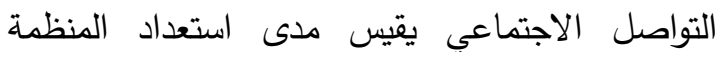

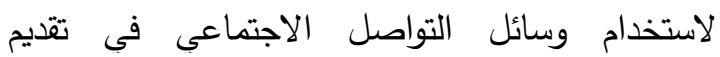
خدماتها، وذلك عن طريق تقييم العائل العاملين بالمنظمة للأبعاد المتعلقة باستخدام وسائل التواصل فلئ الاجتماعى في تقديم خدمات المنظمة. ولتطبيق مقياس استعداد المنظمة لاستخدام وسائل

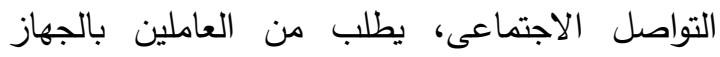

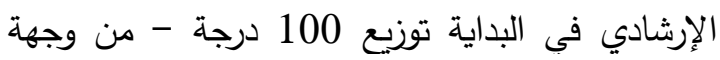

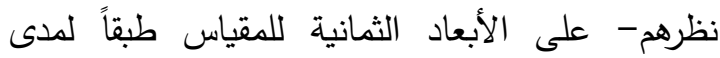

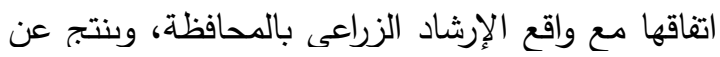

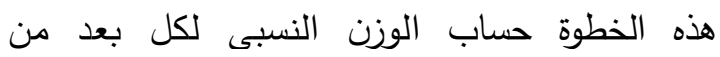
الأبعاد، ثم يتم حساب متوسط درجات العبارات
حيث وسائل التواصل الاجتماعى التى يستخدما الزراع

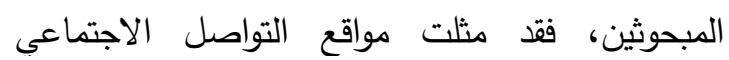
الوسيلة الأكثر استخداما بينهم (90,8\%)، وذلك مقارنة

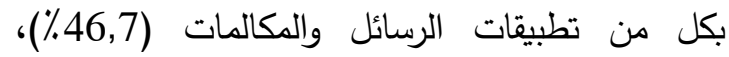
ومواقع مشاركة الفيديو (39,2\%).

ثانياً: استعداد المنظمة الإرشادية بمحافظة أسيوط

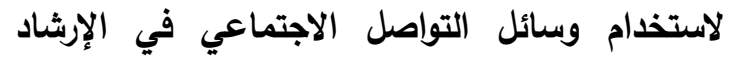
الزراعي 1- تقييم العاملين بالجهاز الإشادي لاستعداد المنظمة الإرشادية بمحافظة أسيوط لاستخدام وسائل الإنل

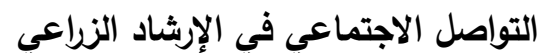

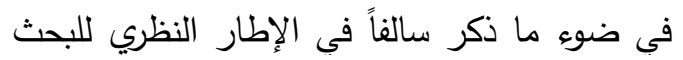

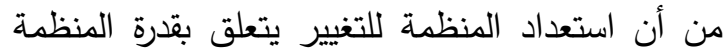


جدول 2. توزيع الزراع المبحوثين طبقاً لخصائصهم المبينة (ن= 120)

\begin{tabular}{|c|c|c|c|}
\hline$\%$ & 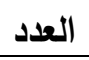 & الخصائص & 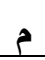 \\
\hline \multicolumn{3}{|r|}{ السن: السن } & \multirow{3}{*}{$\mathbf{1}$} \\
\hline 61,7 & 74 & |أقل من 50 سنة & \\
\hline 38,3 & 46 & | 50 سنة فأكثر & \\
\hline \multicolumn{3}{|r|}{ المؤهل الاراسي: } & 2 \\
\hline 59,2 & 71 & |مؤهل متوسط & \\
\hline 18,3 & 22 & | مؤهل فوق المتوسط & \\
\hline 22,5 & 27 & | مؤهل جامعي & \\
\hline \multicolumn{3}{|r|}{ المهنة: } & 3 \\
\hline 35,8 & 43 & | يعمل بالزراعة كمهنة أساسية & \\
\hline 64,2 & 77 & | يعمل بالزراعة كمهنة ثانوية & \\
\hline \multicolumn{3}{|r|}{ حجم الحيازة المزرعية: } & 4 \\
\hline 33,3 & 40 & | أقل من فدان & \\
\hline 48,4 & 58 & | 1-3 أفدنة & \\
\hline 18,3 & 22 & | 4 أفنتة فاكثر & \\
\hline \multicolumn{3}{|r|}{ وسائل التواصل الاجتماعي المستخدمة: } & 5 \\
\hline 90,8 & 109 & مواقع التواصل الاجتماعي (فيسبوك) & \\
\hline 46,7 & 56 & تطبيقات الرسائل والمكالمات (واتس آب) & \\
\hline 39,2 & 47 & | مواقع مشاركة الفيديو (يوتيوب) & \\
\hline
\end{tabular}

المصدر: إستمارات الإستبيان

يتبين من نفس الجدول انخفاض درجة الاستعداد

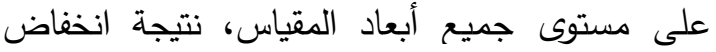

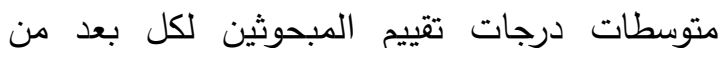

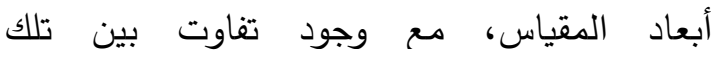
المتوسطات لتبلغ ذروتها داخل بعد التزاد التزام الإدارة نحو

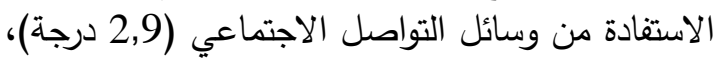
ووصلت لأدناها داخل بعد التحكم والقياس

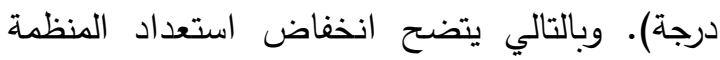

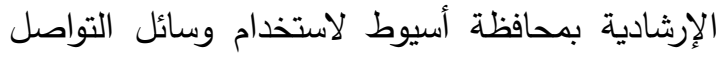

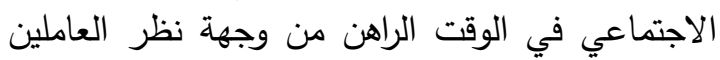

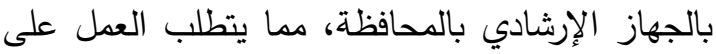
تحسين هذا الاستعداد داخل جميع الأبعاد المدروسة

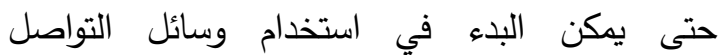
الاجتماعي في تقديم الخذمات الإرشادية بالمحافظة.
داخل كل بعد من أبعاد المقياس، وهو ما يكون الدرجة الحالية، ثم تقسم الدرجة الحالية / 5 لأنهاديا تقاس من خلال مقياس ليكرت خماسى داتئ درجته

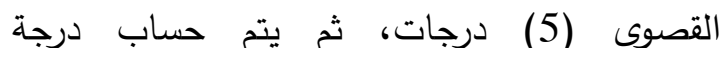
Pein الاستعداد باستخدام المعادلة التى أوضحتهاب درابها .(2013)

درجة الاستعد/د = (الدرجة الحالية / 5) x (100) (100) x

وتثير النتائج الواردة في جدول (3) وشكل (2) إلى انخفاض درجة استعداد المنظمة الإرشادية بمحافظة أسيوط لاستخدام وسائل التواصل الاجتماعى الإنى الإنظي

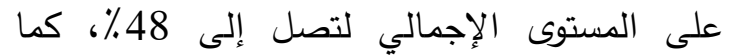


جدول 3. متوسطات درجات تقييم العاملين بالجهاز الإششادي بمحافظة أسيوط لأبعاد مقياس استعداد المنظمة لاستخدام وسائل التواصل الاجتماعي درب تصيم

\begin{tabular}{|c|c|c|c|c|}
\hline الاستعد اد & 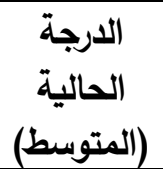 & 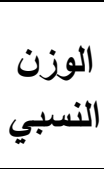 & أبعاد مقياس استعداد المنظمة لاستخدام وسائل التواصل & b \\
\hline 12,5 & 2,9 & 21,5 & التزام الإدارة نحو الإستفادة من وسائل التواصل الاجتماعي & 1 \\
\hline 10,6 & 2,7 & 19,6 & المعرفة بوسائل التواصل الاجتماعي & 2 \\
\hline 6,9 & 2,2 & 15,7 & اندماج العملاء المستهدفين & 3 \\
\hline 4,4 & 2,1 & 10,4 & النظرة التتافسية & 4 \\
\hline 8,9 & 2,5 & 17,7 & توافر الإمكانيات اللازمة & 5 \\
\hline 1,8 & 1,7 & 5,3 & التخطيط واختيار القنوات المناسبة & 6 \\
\hline 1,6 & 1,6 & 5,1 & ت توثيق التقدم الحادث & 7 \\
\hline 1,3 & 1,4 & 4,7 & التحكم والقياس & 8 \\
\hline \multicolumn{3}{|c|}{$\% 48$} & إجمالي درجة الاستعد اد & \\
\hline
\end{tabular}

المصدر: إستمارات الإستبيان

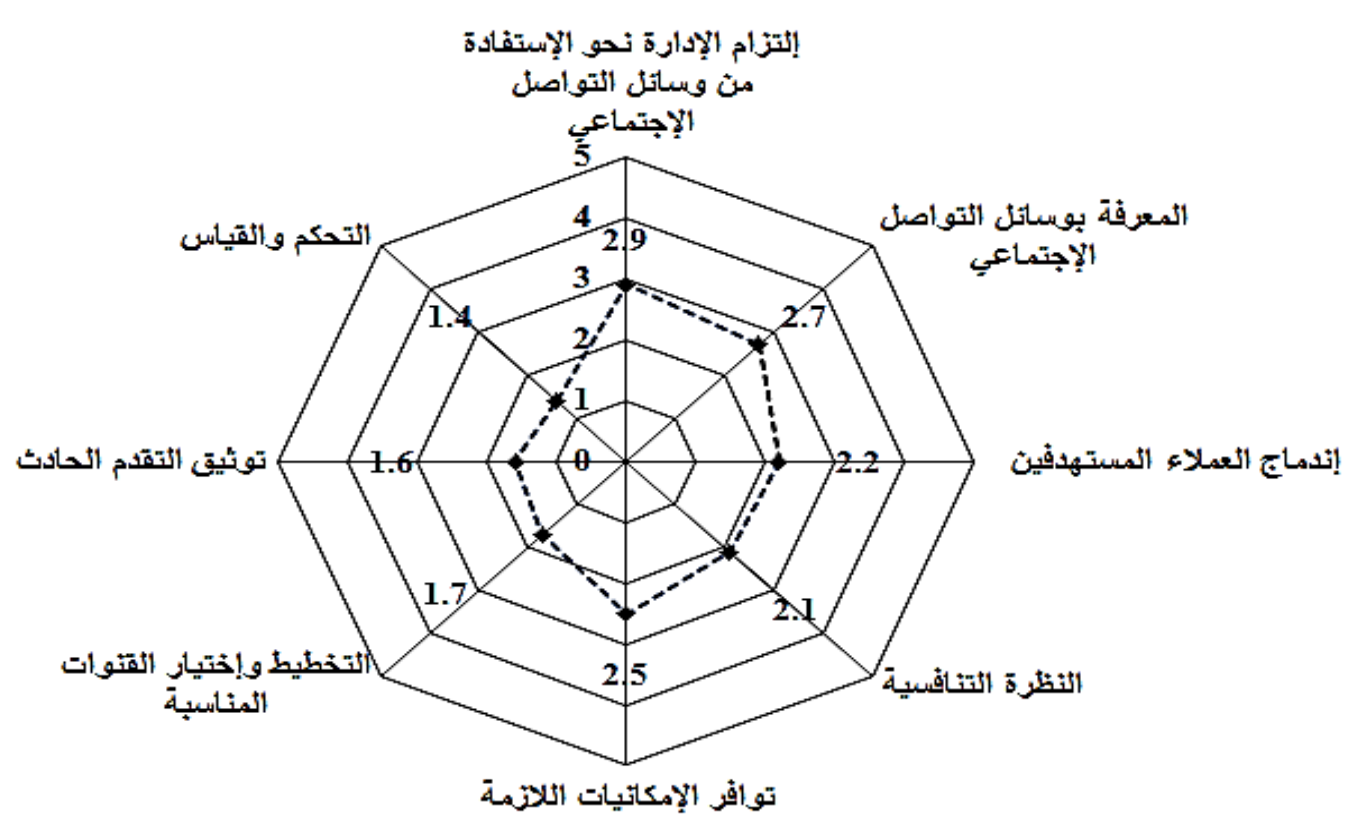

شكل 2. متوسطات درجات تقييم العاملين بالجهاز الإرشادي بمحافظة أسيوط لأبعاد مقياس استعداد المنظمة

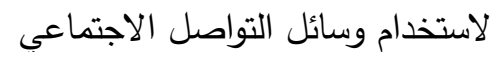
المصدر: إستمارات الإستبيان 
أن متغير الفوائد الاجتماعية حصل على الدرجة

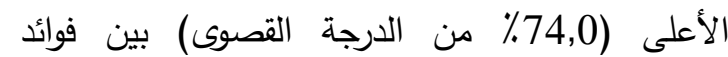

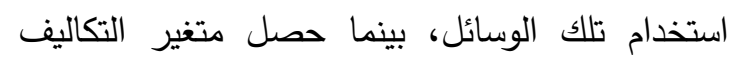

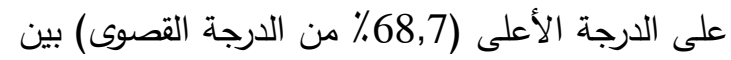

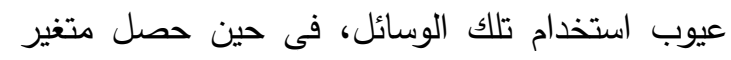

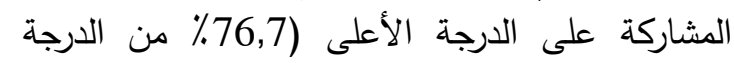

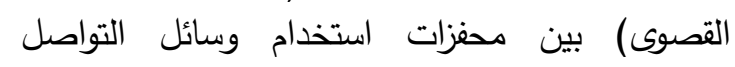
الاجتماعي في الإرشاد الزراعى.

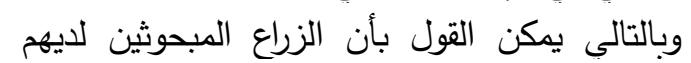

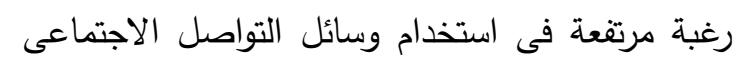

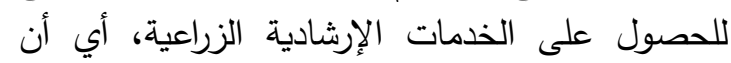

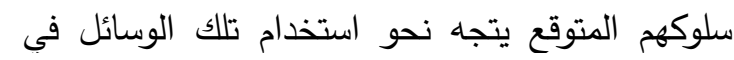
حالة بداية أي مبادرة لتقديم المعلومات الإرشادية عن التئل طريق وسائل التواصل الاجتماعي. كما يتبين أن هؤلاء

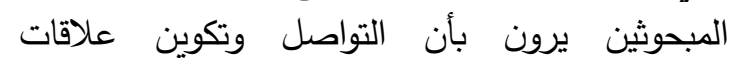
اجتماعية جديدة هي أهم الفوائد المرتبطة باستخدام

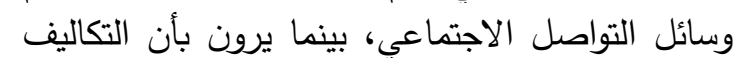

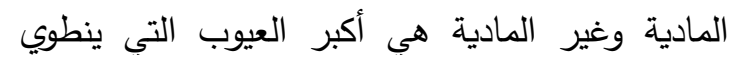

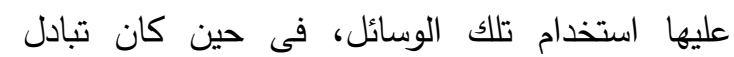

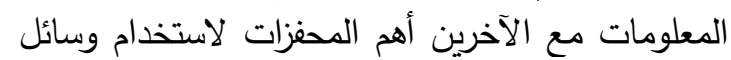

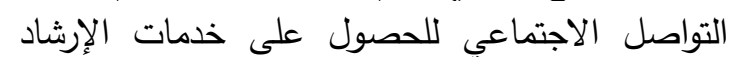

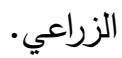

2- المتغيرات المؤثرة على رغبة الزراع المبحوثين في

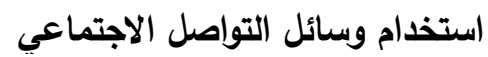

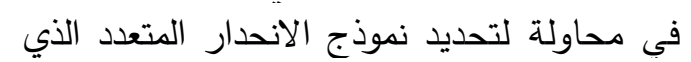

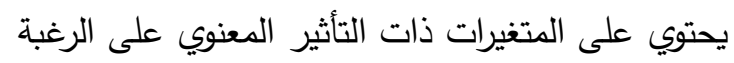

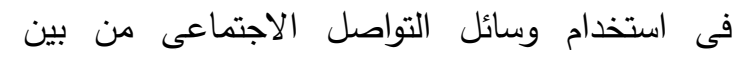

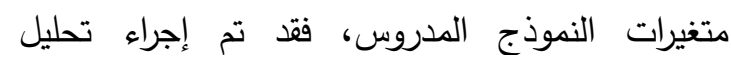
Stepwise Multiple الانحدار المتعدد المرحلي المدوني، Regression Analysis

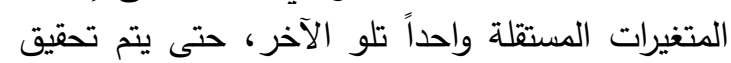

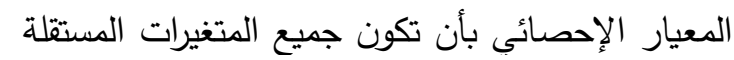

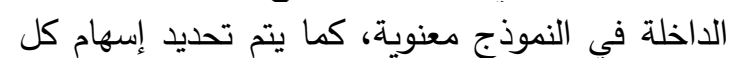

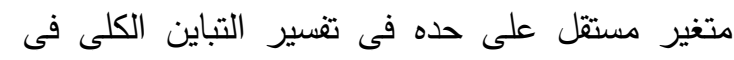

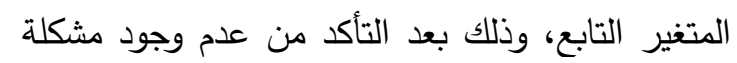
الارتباط الخطي المتعدد Multicollinearity تعني الإرتباط القوي بين المتغيــرات المستقلة وبعضها
2- كيفية تحسين استعداد المنظمة الإرشادية لاستخدام وسائل التواصل الاجتماعي في الإرشاد الإثيادي الزراعي

بعد الانتهاء من قياس استعداد المنظمة لاستخدام

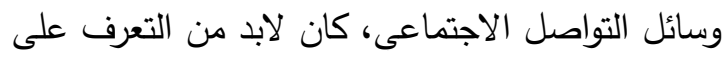
كيفية تحسين هذا الاستعداد على مستوى جميع أبعاد الادي المقياس، ويتم ذلك في صورة دليل يتضمن هذين مجموعة

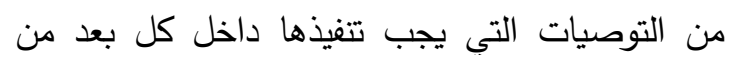

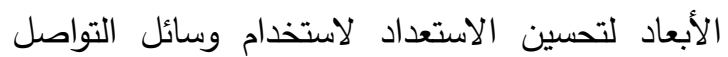

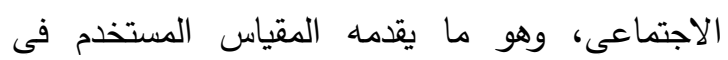
خطوته الأخيرة مباشرة داخل ملف Excel بناء لفئه على

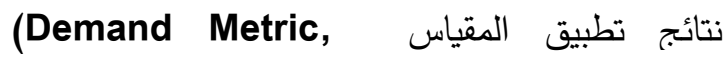
(2009. وبناءً على نتائج الدراسة الحالية، يوضح الئح

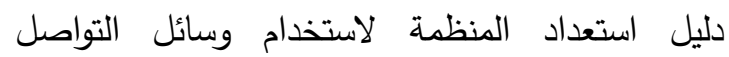

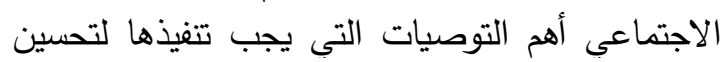

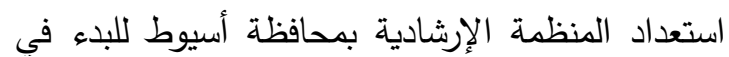

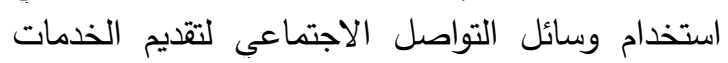

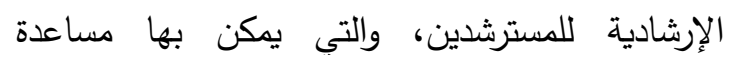

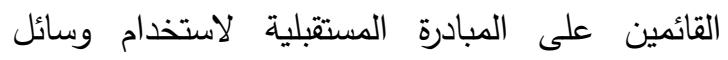
التواصل الاجتماعي في الإرشاد الزراعي بمحافظة لإنة

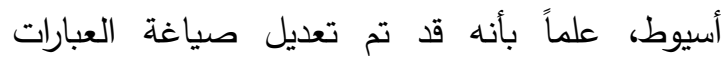

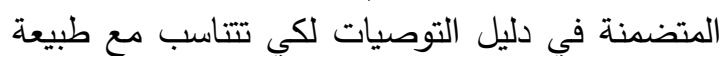

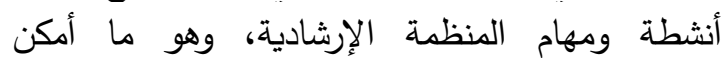
تلخيصه في شكل (3).

ثالثاً: الرغبة في استخدام وسائل التواصل الاجتماعي في الإرشاد الزرأعي الرغي

1- رغبة الزراع المبحوثين في استخدام وسائل التواصل الاجتماعي للحصول على الزئل الخدمات الإرثادية الزراعية يوضح جدول (4) متوسطات إدراكات الزراع المبحوثين لمتغيرات مقياس الرغبة في استخدام وسائل

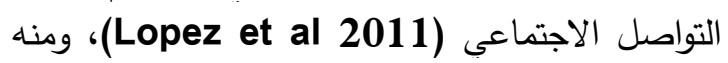
يتبين أن متوسط درجة رغبة الزراع لاستخدام وسائل

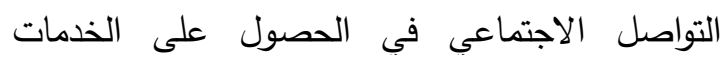

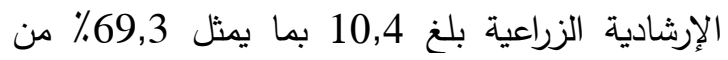
الدرجة القصوى. وتوضح النتائج الواردة بنفس الجدول بـأل 

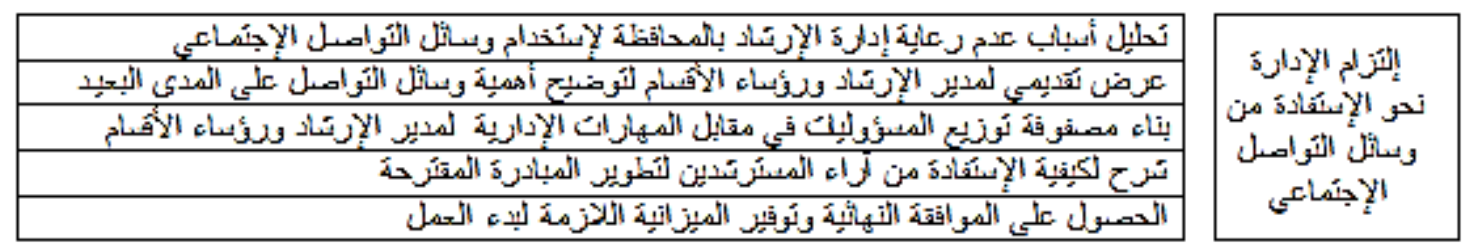

\begin{tabular}{|c|}
\hline 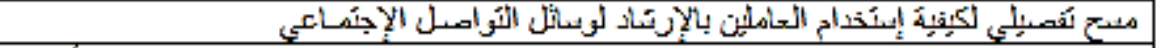 \\
\hline 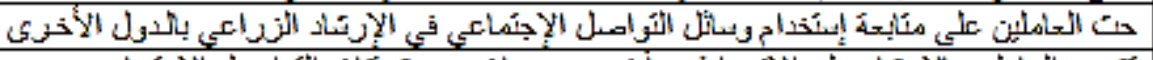 \\
\hline 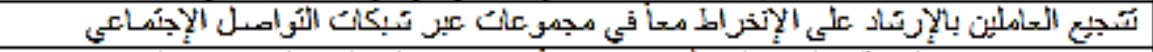 \\
\hline
\end{tabular}

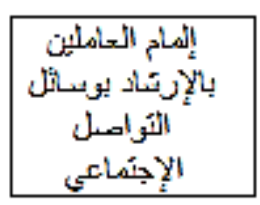

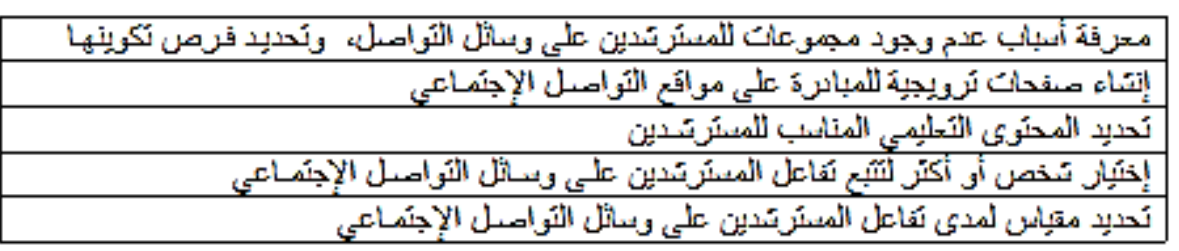

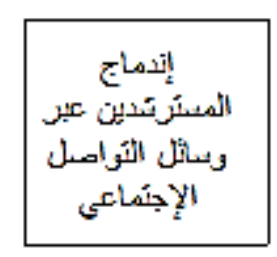

\begin{tabular}{|c|}
\hline 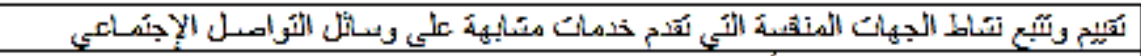 \\
\hline 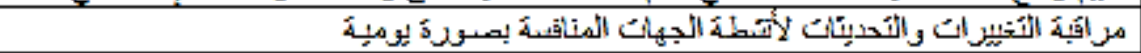 \\
\hline 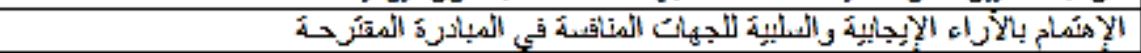 \\
\hline 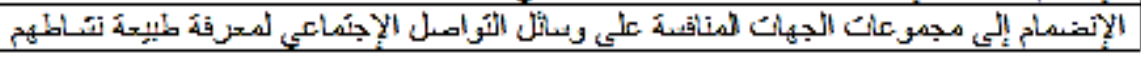 \\
\hline
\end{tabular}

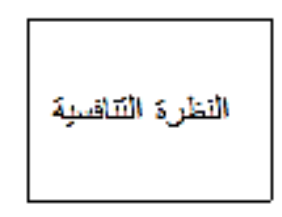

\begin{tabular}{|c|}
\hline 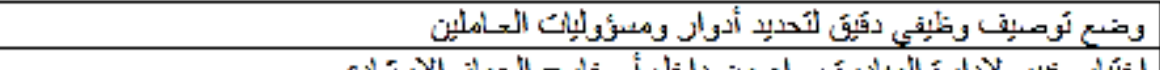 \\
\hline 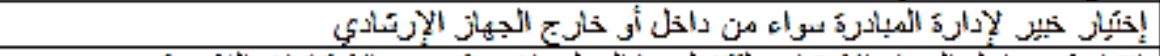 \\
\hline 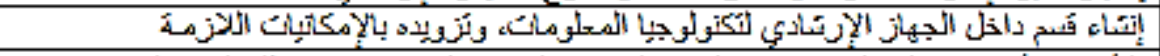 \\
\hline 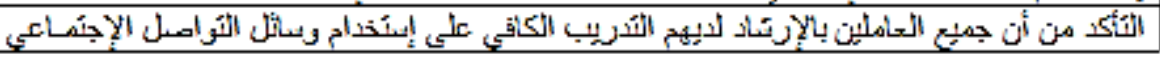 \\
\hline
\end{tabular}

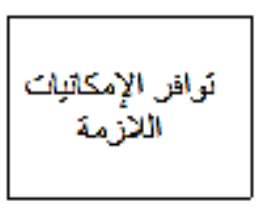

\begin{tabular}{|c|}
\hline 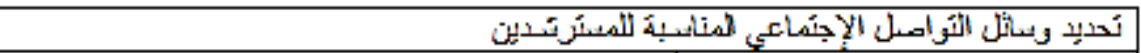 \\
\hline 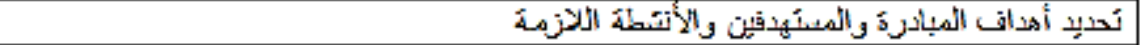 \\
\hline 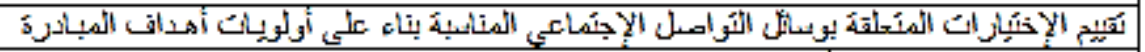 \\
\hline 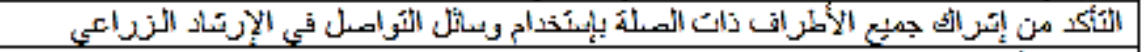 \\
\hline 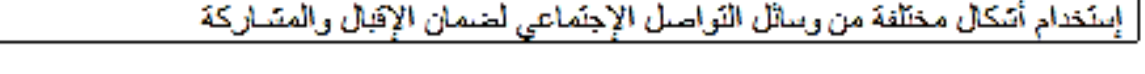 \\
\hline
\end{tabular}

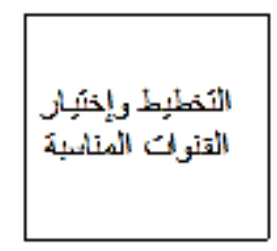

\begin{tabular}{|c|}
\hline 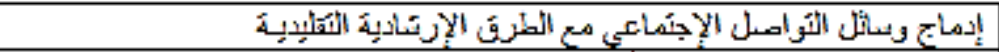 \\
\hline 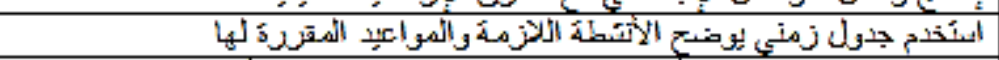 \\
\hline 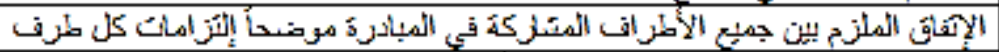 \\
\hline 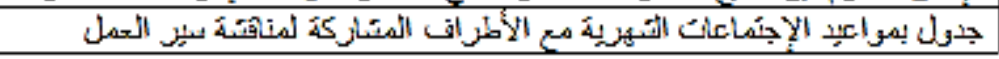 \\
\hline
\end{tabular}

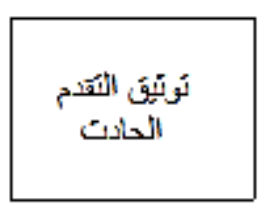

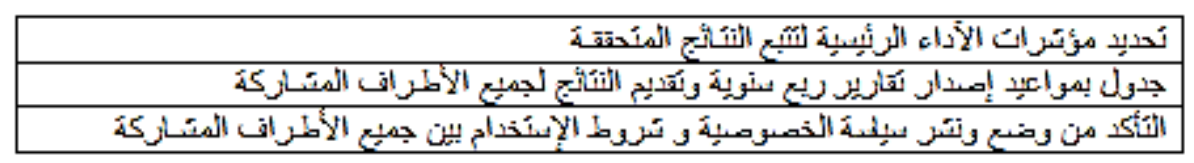

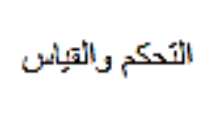

شكل 3. التوصيات المتعلقة بكيفية تحسين استعداد المنظمة الإرشادية لاستخدام وسائل التواصل الاجتماعي في الإرشاد الزراعي بمحافظة أسيوط التصليات المصدر : مستخلص من (Demand Metric, 2009) بناءً على نتائج الدراسة الحالية 
دراسة لجاهزية استخدام وسائل التواصل الاجتماعي في الإرشاد الزراعي بمحافظة أسيوط 1795

جدول 4. متوسطات إدراكات الزراع المبحوثين لمتغيرات مقياس الرغبة في استخدام وسائل التواصل الاجتماعي

\begin{tabular}{|c|c|c|c|c|}
\hline$\%$ & القصوجة & المتوسط & متغيرات مقياس الرغبة في استخدام وسائل التواصل الاجتماعي & p \\
\hline 63,3 & 15 & 9,5 & الفوائد المهنية & 1 \\
\hline 69,0 & 10 & 6,9 & الفوائد النفسية & 2 \\
\hline 74,0 & 15 & 11,1 & الفوائد الاجتماعية & 3 \\
\hline 68,7 & 15 & 10,3 & التكاليف & 4 \\
\hline 61,3 & 15 & 9,2 & فقدان الخصوصية & 5 \\
\hline 57,0 & 10 & 5,7 & صعوبة الاستخدام & 6 \\
\hline 76,7 & 15 & 11,5 & المشاركة & 7 \\
\hline 50,7 & 15 & 7,6 & إمكانية الوصول & 8 \\
\hline 43,3 & 15 & 6,5 & البيئة المحيطة & 9 \\
\hline 72,7 & 15 & 10,9 & الاهتمام & 10 \\
\hline 66,0 & 10 & 6,6 & الثقة & 11 \\
\hline 69,3 & 15 & 10,4 & الرغبة في الاستخدام & 12 \\
\hline
\end{tabular}

المصدر: إستمارات الإستبيان

قيمة معامل التحديد للنموذج ككل 0,618 وقيمة

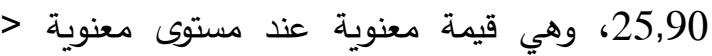

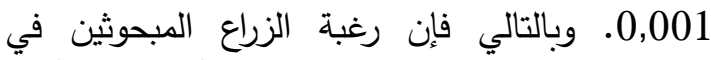
استخدام وسائل التواصل الاجتماعي تتأثر بشكل أكبر

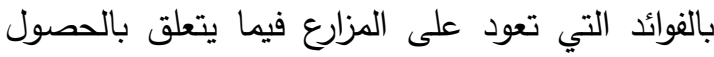

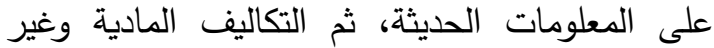
المادية المتوقعة لاستخدام تلك الوسائل، ثم اعتبار تلك الوسائل مصدر موثوق للمعلومات، ثم تبادل المعلومات والخبرات مع الآخرين، ثم الميل لتجريب الأثياء

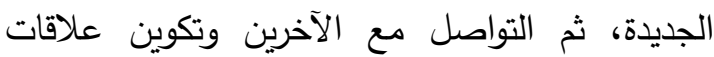
اجتماعية جديدة، ثم صعوبة البحث عن المعلومات التين ونكوين واختلاف الآراء بين الأفراد.

رابعاً: آراء المبحوثين حول مزايا ومعوقات ومقترحات

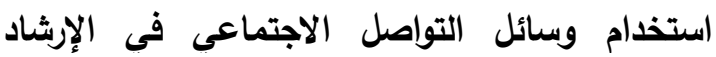
الزراعى تم التعرف على آراء فئتي المبحوثين من العاملين بالإرشاد الزراعى والزراع حول استخدام وسائل التواصل

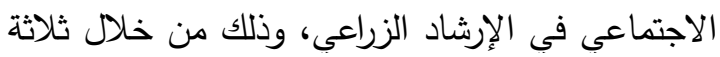
أسئلة مفتوحة حول مزايا ومعوقات ومقترحات استخدام الإنيات

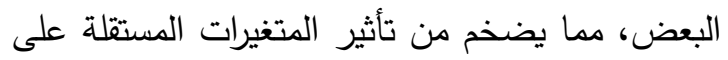

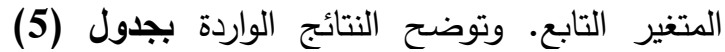
ترتيب دخول المتغيرات في نموذج الانحدار، ومنه يتبين أن متغير الفوائد المهنية كان أول فئ المتغيرات

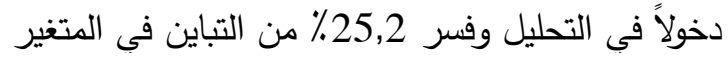

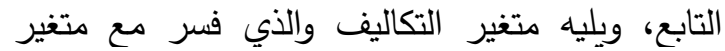
الفوائد المهنية 45,1\% من التباين في المتغير التابع، وهكذا حتى دخول المتغير السابع وهو متغير الصعوبة الصنية والذي فسر مع المتغيرات السابقة 61,8٪ من التباين في المتغير التابع، كما استبعد التحليل أربعة متغيرات من النموذج (الفوائد النفسية، وفقدان الخصية النصوصية، وإمكانية الوصول، والبيئة المحيطة) لعدم معنوية تأثيرها

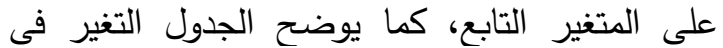
معامل التحديد، والذي يدل على مقدار ما يساهم به يه

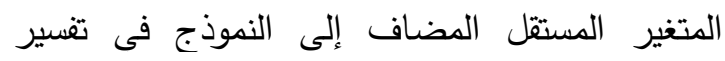
التباين في المتغير التابع، ثم قيمة (F) لمعنوية التغير فئنير في معامل التحديد. وتبين النتائج الواردة بنفس الجدول أن المتغيرات

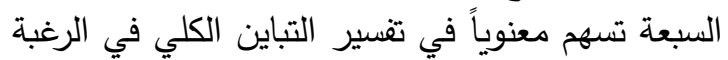

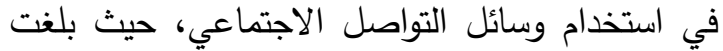


جدول 5. نتائج تحليل الانحدار المتعدد المرحلي للمتغيرات المؤثرة على رغبة الزراع المبحوثين في استخدام وسائل التواصل الاجتماعي

\begin{tabular}{|c|c|c|c|c|c|}
\hline مستوى المعنوية & قيمة F & التغير في & 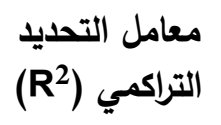 & في نموذيب دخول المتغيرات & خطوات التحليل \\
\hline 0,000 & 39,72 & 0,252 & 0,252 & الفوائد المهنية & 1 \\
\hline 0,000 & 42,51 & 0,199 & 0,451 & التكاليف & 2 \\
\hline 0,000 & 16,43 & 0,068 & 0,519 & الثقة & 3 \\
\hline 0,003 & 9,14 & 0,036 & 0,555 & المشاركة & 4 \\
\hline 0,019 & 5,66 & 0,021 & 0,576 & الاهتمام & 5 \\
\hline 0,008 & 7,33 & 0,026 & 0,602 & الفوائد الاجتماعية & 6 \\
\hline 0,030 & 4,85 & 0,016 & 0,618 & الصعوبة & 7 \\
\hline
\end{tabular}

المصدر: إستمارات الإستبيان معامل التحديد للنموذج ككل (R2

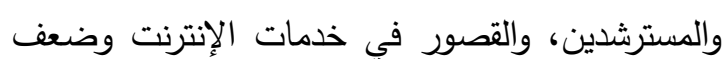

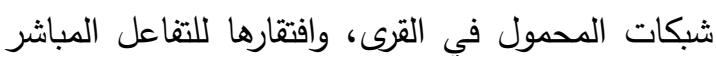
بين المرشد والمسترشد، وصعوبة المراقبة والتحكم في في في محتواها المعلوماتي، بينما اضاف العاملين بالإرشاد لتلك المعوقات المشتركة عدم توافر الإمكانيات اللازمة

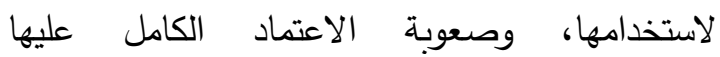
والاستغناء عن الإرشاد التقليدي، في حين ذكر الزراع أن المحتوى المعلوماتي المقدم عن طريق تلك الوسائل قد لا يتتاسب مع المشاكل والحاجات المحلية. وأخيراً فقد تشارك المبحوثون من العاملين بالإرشاد والزراع في وجهات نظرهم حول أغلب المقترحات اللازمة لإنجاح استخدام وسائل التواصل الاجتماعي في وجي الإرشاد الزراعي، مثل عقد ندوات إرشادية لتوعية

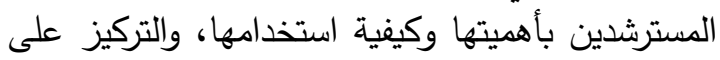

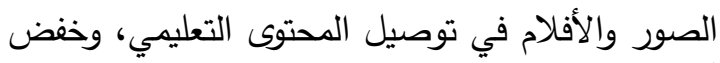
أسعار خدمة الإنترنت على الهاتف المحمول، وتوصيل توصيل وخلئ

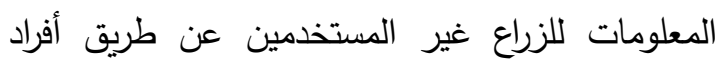
أسرهم المستخدمين لتلك الوسائل، وأضاف العاملين بالإرشاد للمقترحات السابقة ضرورة توفير الإمكانيات اللازمة عن طريق تزويد الإدارات الزراعية والجمعيات

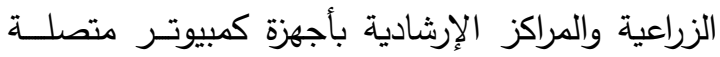

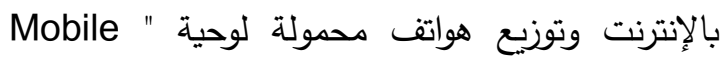

وسائل التواصل الاجتماعي في الإرشاد الزراعي. ففيما يتعلق بمزايا استخدام وسائل التواصل الاجتماعي في في الإدئي

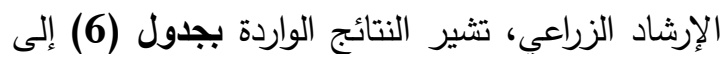

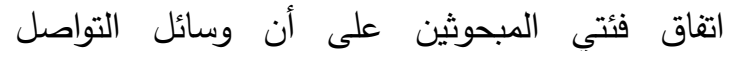

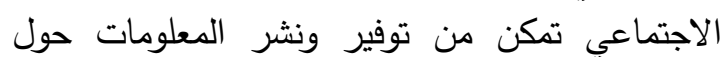

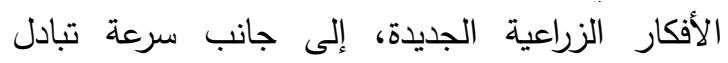
المعلومات في أي وقت وأي مكان، كما اظهرت النتائج

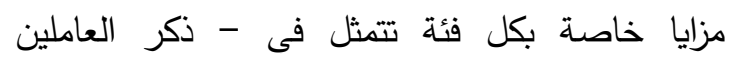

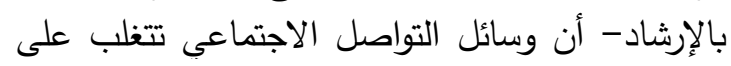

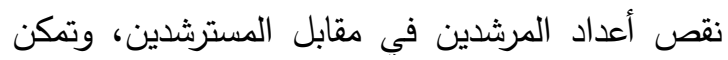

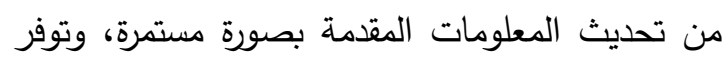
وقت وجها وتكاليف الاتصال بالمسترشدين، في حين يرى الزراع أن تلك الوسائل تعتبر بديل للإرشاد التقليدي

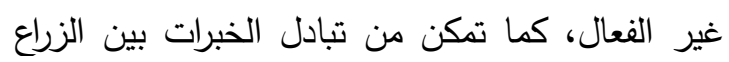
وبعضهم البعض. أما فيما يتعلق بمعوقات استخدام وسائل التواصل

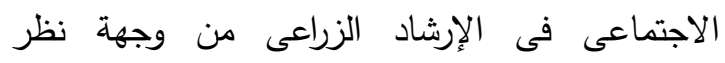

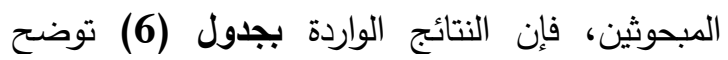
اتفاق فئتي المبحوثين على أغلب المعوقات التي تحد

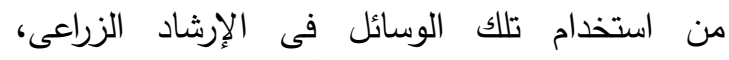
والمتمثلة في ارتفاع نسبة الأمية بين المسترشدين،

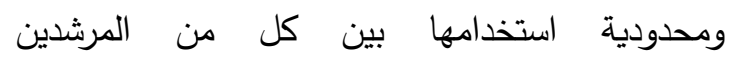


دراسة لجاهزية استخدام وسائل التواصل الاجتماعي في الإرشاد الزراعي بمحافظة أسيوط

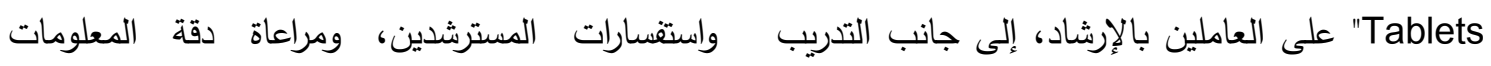

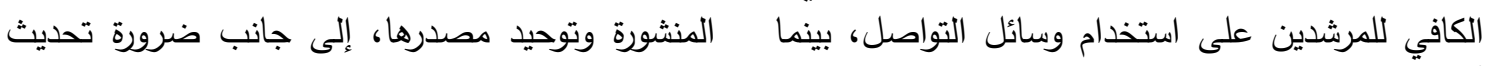
أشار الزراع لضرورة سرعة الرد على مشاكل المحتوى المقدم وربطه بمشاكل وحاجات الزراع. جدول 6. آراء المبحوثين حول استخدام وسائل التواصل الاجتماعي في الإرشاد الزراعي

\begin{tabular}{|c|c|c|c|c|c|}
\hline \multicolumn{2}{|c|}{$\begin{array}{c}\text { (الزراع } \\
(120=0\end{array}$} & \multicolumn{2}{|c|}{ 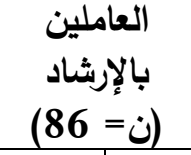 } & \multirow[t]{2}{*}{ آراء المبحوثين حول استخدام وسائل التواصل الاجتماعي في الإششاد } & \multirow[t]{2}{*}{ p } \\
\hline$\%$ & 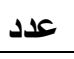 & $\%$ & عدد & & \\
\hline \multicolumn{6}{|c|}{ مزايا استخدام وسائل التواصل الاجتماعي في الإرشاد الزراعي } \\
\hline 42,5 & 51 & 70,9 & 61 & توفير ونشر المعلومات حول الأفكار الزراعية الجديدة & 1 \\
\hline 56,7 & 68 & 24,4 & 21 & سرعة تبادل المعلومات في أي وقت وأي مكان & 2 \\
\hline- & - & 67,4 & 58 & التغلب على نقص أعداد المرشدين في مقابل المسترشدين & 3 \\
\hline- & - & 53,5 & 46 & تحديث المعلومات المقدمة بصورة مستمرة & 4 \\
\hline- & - & 37,2 & 32 & توفير وقت وجهد وتكاليف الاتصال بالمسترشدين & 5 \\
\hline 35,8 & 43 & - & - & تعتبر بديل للإرشاد التقليدي غير الفعال & 6 \\
\hline 22,5 & 27 & - & - & إمكانية تبادل الخبرات بين الزراع وبعضهم البعض & 7 \\
\hline \multicolumn{6}{|c|}{ معوقات استخدام وسائل التواصل الاجتماعي في الإرشاد الزراعي } \\
\hline 30,8 & 37 & 61,6 & 53 & ارتقاع نسبة الأمية بين المسترشدين & 1 \\
\hline 40,8 & 49 & 51,2 & 44 & محدودية استخدامها بين المرشدين أو المسترشدين & 2 \\
\hline 38,3 & 46 & 45,3 & 39 & القصور في خدمات الإنترنت وضعف شبكات المحمول في القرى & 4 \\
\hline 16,7 & 20 & 32,6 & 28 & افتقارها للتفاعل المباشر بين المرشد والمسترشد & 3 \\
\hline 9,2 & 11 & 15,1 & 13 & صعوبة المراقبة والتحكم في المحتوى & 5 \\
\hline- & - & 68,6 & 59 & عدم توافر الإككانيات اللازمة لاستخدامها & 6 \\
\hline- & - & 25,6 & 22 & صعوبة الاعتماد الكامل عليها والاستغناء عن الإرشاد التقليدي & 7 \\
\hline 23,3 & 28 & - & - & عدم مناسبة المحتوى مع المشاكل والحاجات المحلية & 8 \\
\hline \multicolumn{6}{|c|}{ مقترحات إنجاح استخدام وسائل التواصل الاجتماعي في الإرشاد الزراعي } \\
\hline 15,8 & 19 & 38,4 & 33 & عقد ندوات إرشادية لتوعية المسترشدين بأهميتها وكيفية استخدامها & 1 \\
\hline 34,2 & 41 & 27,9 & 24 & التركيز على الصور والأفلام في توصيل المحتوى التعليمى & 2 \\
\hline 31,7 & 38 & 23,3 & 20 & تخفيض أسعار خدمة الإنترنت على الهاتف المحمول & 3 \\
\hline 22,5 & 27 & 17,4 & 15 & توصيل المعلومات للزراع غير المستخدمين عن طريق أفراد أسرهم & 4 \\
\hline- & - & 63,9 & 55 & توفير أجهزة كمبيوتر متصلة بالإنترنت وهواتف محمولة لوحية للمرشدين & 5 \\
\hline- & - & 55,8 & 48 & التدريب الكافى للمرشدين على استخدام وسائل التواصل الاجتماعى & 6 \\
\hline 48,3 & 58 & - & - & سرعة الرد على مشاكل واستفسارات الزراع & 7 \\
\hline 37,5 & 45 & - & - & مراعاة دقة المعلومات المنشورة وتوحيد مصدرها & 8 \\
\hline 21,7 & 26 & - & - & تحديث المحتوى المقدم وربطه بمشاكل وحاجات الزراع & 9 \\
\hline
\end{tabular}


عن طريق أفراد أسرهم المستخدمين لتلك الوسائل، مع

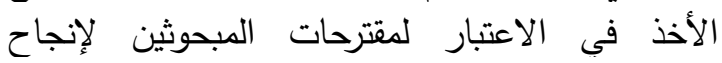
استخدام وسائل التواصل الاجتمارعي في تقديم الخدمات لإتيات الإرشادية الزراعية.

وفيما يتعلق بوسائل التواصل الاجتماعي التي يمكن الإني استخدامها لتقديم المعلومات الإرشادية، يمكن التوصية التئية

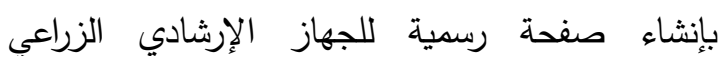

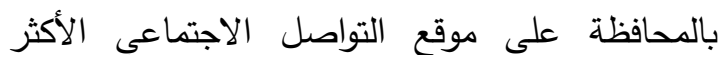

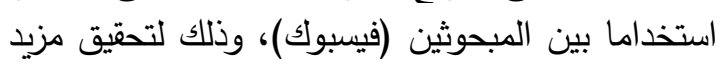

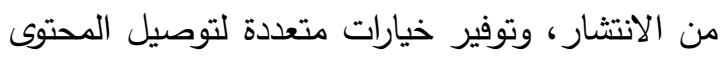

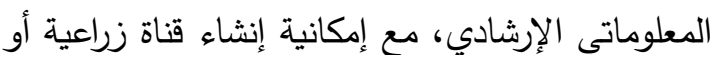

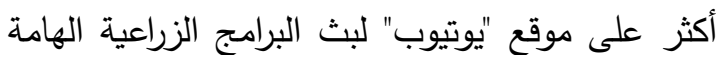

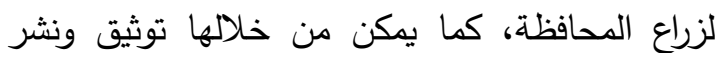

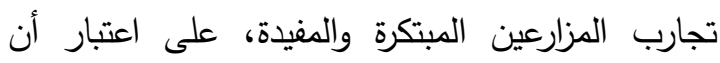

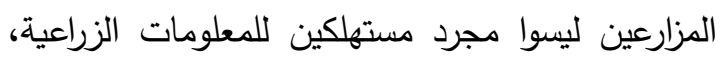

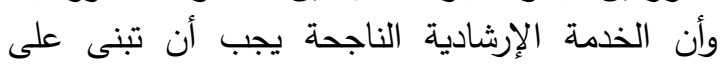

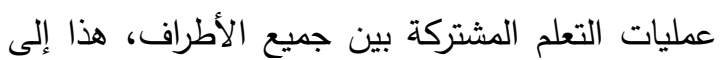

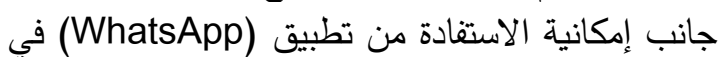
تسهيل عملية الاتصال الإرشادي، وإرسال والطنين (إستقبال المعلومات من وإلى المسترشدين بالمحافظة.

$$
\text { المراجـع }
$$

\section{المراجع الاجنبيه}

Alvi M. 2016. A manual for selecting sampling techniques in research, Munich Personal RePEc Archive, Paper No. 70218. Available at: https://mpra.ub.unimuenchen.de/70218/1/MPRA paper 70218.pdf

Amin K. and Li J. 2013. Applying farmer technology acceptance model to understand farmers' behavioral intention to use ICT based microfinance platform: A comparative analysis between Bangladesh and China, The Thirteenth Wuhan International Conference on EBusiness-IT/IS Technology for EBusiness. Available at: https://pdfs.semanticscholar.org/8c3c/ bcf6aaae89c08395ebb0eae7ae448d5 74978.pdf

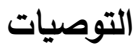

بداية يمكن القول بأن وسائل التواصل الاجتماعى التي

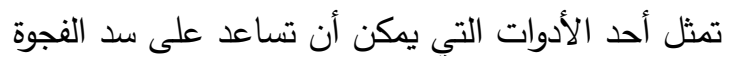

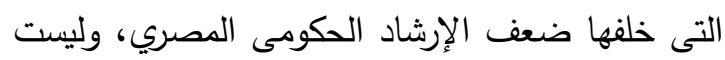

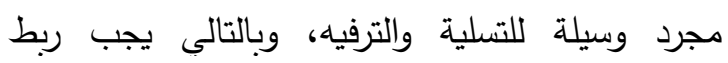
استخدام وسائل التواصل الاجتماعى بتحقيق أهداف

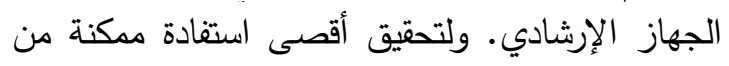

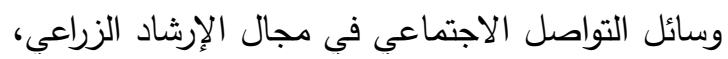

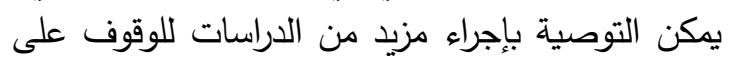

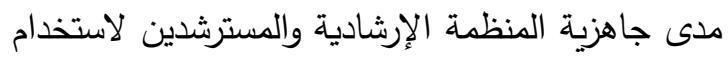

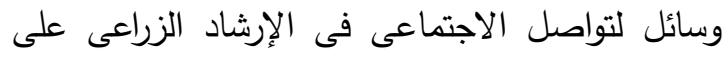
مستوى الجمهورية من ناحية، وإمكانية شمول المبادية المبادرة الرئي

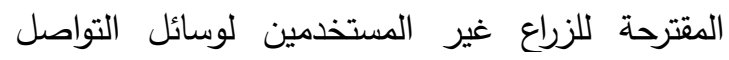
الاجتماعي عن طريق أفراد أسرهم المستخدمين لتلكين لتصني

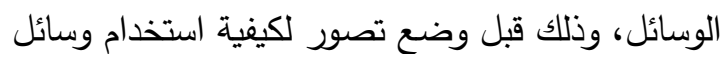
التواصل الاجتماعي لتقديم الخدمات الإششادية للمسترشدين.

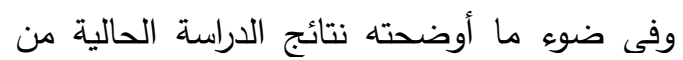

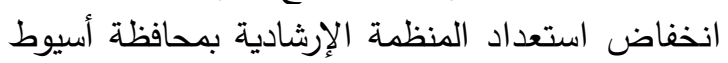

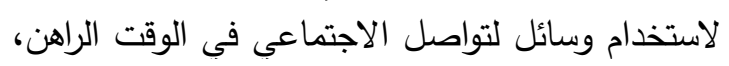

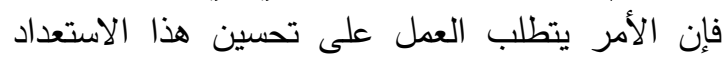

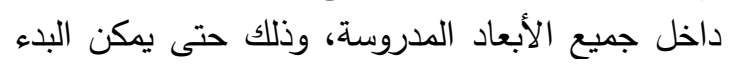

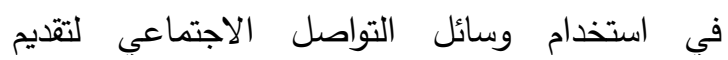
الخدمات الإرشادية بالمحافظة، ويمكن الاستفادة في التئي

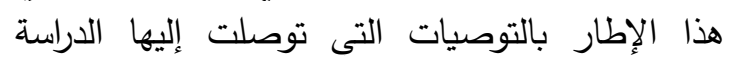

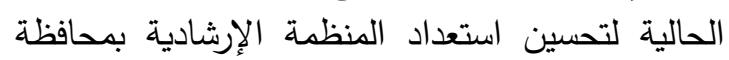

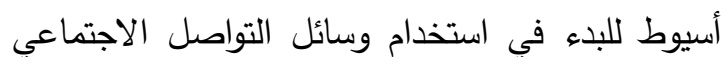
في تقديم الخدمات الإرشادية للمسترشدين.

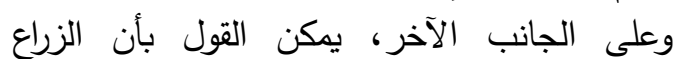

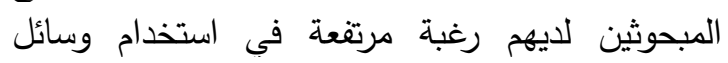

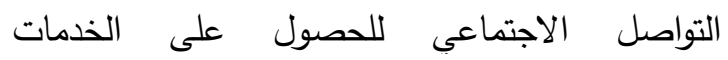

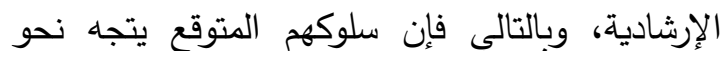

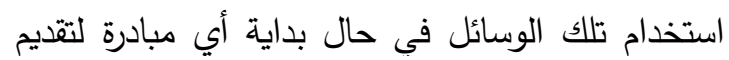

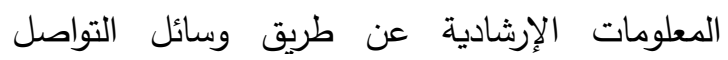
الاجتماعي، بما يمثل فرصة للتفكير في مبادرة مبدئية

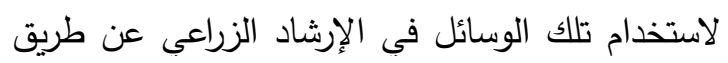

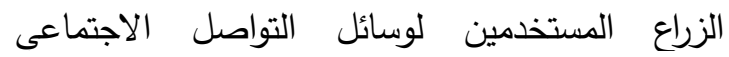

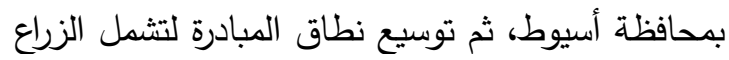

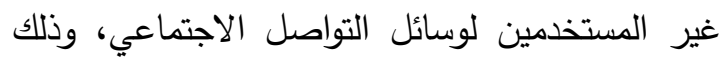


Armenakis A., Harris S. and Mossholder K. 1993. Creating readiness for organizational change, Human Relations, 46(3), 681-703. Available at: https://journals.sagepub.com/doi/pdf/1 $0.1177 / 001872679304600601$

Bernerth J. 2004. Expanding our understanding of the change message, Human Resource Development Review 3(1), 36-52. Available at: https://journals.sagepub.com/doi/pdf/1 $0.1177 / 1534484303261230$

Berry A. 2017. Behavioral intention and use behavior of social networking websites among senior adults, PhD. Thesis, Nova Southeastern University, USA. Available at: https://nsuworks.nova.edu/cgi/viewcon tent.cgi?article $=2023 \&$ context $=$ gscis e $\underline{\text { td }}$

Bhattacharjee B. and Saravanan R. 2016. Social media: Shaping the future of agricultural extension and advisory services, GFRAS: Lindau, Switzerland. Available at: https://www.gfras.org/en/knowledge/gfraspublications.html?download=414: socia I-media-shaping-the-future-ofagricultural-extension-and-advisoryservices

Boone H. and Boone D. 2012. Analyzing Likert data, J. of Extension, 50(2). Available at: http://www.joe.org/joe/2012april/tt2.ph p

Cornelisse S., Hyde J., Raines C., Kelley K., Ollendyke D. and Remcheck J. 2011. Entrepreneurial extension conducted via social media, Journal of Extension, 49(6). Available at:

https://www.joe.org/joe/2011december /tt1.php

Demand Metric. 2009. Social Media Readiness Assessment, Ontario, Canada. Available at: https://christinck.de/wpcontent/uploads/sites/6/2015/09/Social MediaReadyness.xIsx

Dixit R. and Prakash G. 2018. Intentions to use social networking sites (SNS) using technology acceptance model (TAM): An empirical study, Paradigm, 22(1), 65-79. Available at: https://journals.sagepub.com/doi/pdf/1 $0.1177 / 0971890718758201$

FAO. 2017. Information and communication technology (ICT) in agriculture: A report to the G20 agricultural deputies, Rome. Available at: http://www.fao.org/3/a-i7961e.pdf

Fuess L. 2011. An analysis and recommendations of the use of social media within the cooperative extension system: Opportunities, risks, and barriers, Honors Thesis, Cornell University, New York. Available at: https://ecommons.cornell.edu/handle/1 813/23129

Gharis L., Bardon R., Evans J., Hubbard W. and Taylor E. 2014. Expanding the reach of extension through social media, J. of Extension, 52(3), . Available at: https://joe.org/joe/2014june/a3.php

Hoffmann, C., Lutz, C. and Meckel, M. 2013. Social media readiness in public administration: Developing a research framework, IRSPM Annual Conference, Prague. Available at: https://papers.ssrn.com/sol3/papers.cf m?abstract id=2408737

Lopez E., Gidumal J., Tano D. and Armas R. 2011. Intentions to use social media in organizing and taking vacation trips, Computers in Human Behavior, 27, 640-654. Available at: https://www.sciencedirect.com/science larticle/pii/S0747563210001615

Pein V. 2013. Social media manager, Rheinwerk Computing, Germany. Available at: https://dersocialmediamanager.de/social-mediareadiness-score/ 
Saravanan R. and Bhattacharjee S. 2013. Mobile phone and social media for agricultural extension: Getting closer to Hype \& Hope?, International Conference on Extension Educational Strategies for Sustainable Agricultural Development, University of Agricultural Sciences, Bangalore, India. Available at:

http://www.academia.edu/8290165/Mo bile Phone and Social Media for A gricultural Extension Getting Closer to Hype and Hope

Saravanan R. and Bhattacharjee S. 2017. Social media for agricultural extension, Extension Net Bulletin No. 1, National Institute of Agricultural Extension Management, India. Available at: http://www.manage.gov.in/publications lextnnext/March2017.pdf

Setiawan R. and Setyohadi D. 2018. Understanding customers' intention to use social network sites as complaint channel: An analysis of young customers' perspectives, E3S Web of Conferences $\mathbf{3 1}$ p. Available at: https://www.e3s-

conferences.org/articles/e3sconf/pdf/2 018/06/e3sconf icenis2018 11014.pdf

Sokoya A., Onifade F. and Alabi A. 2012. Establishing connections and networking: The role of social media in agricultural research in Nigeria, IFLA World Library and Information Congress, Finland. Available at: https://www.ifla.org/pastwlic/2012/205-sokoya-en.pdf

Stanley S. 2013. Harnessing social media in agriculture, A Report for the New Zealand Nuffield Farming Scholarship Trust, New Zealand. Available at: https://www.nuffield.org.nz/uploads/me dia/S Stanley 2013 Final Report.pdf
Thakur D. and Chander M. 2018. Use of social media in agricultural extension: Some evidences from India, International Journal of Science \& Environment, 7(4), 1334-1346.

Available at: https://www.researchgate.net/publication/3 26802477 USE OF SOCIAL MEDIA IN AGRICULTURAL EXTENSION SOME EVIDENCES FROM INDIA

The World Bank. 2017. ICT in agriculture: Connecting smallholders to knowledge, networks, and institutions, Report Number 64605, Washington, D.C. Available at: http://documents.worldbank.org/curate d/en/522141499680975973/pdf/11731 9-PUB-Date-6-27-2017-PUBLIC.pdf

Venkatesh V., and Davis F. 2000. A theoretical extension of the technology acceptance model: Four longitudinal field studies, Management Sci. 46(2), 186-204. Available at: http://www.vvenkatesh.com/wpcontent/uploads/dlm uploads/2015/11/ MS Venkatesh Davis.pdf

We Are Social LTD. 2018. Global digital report 2018, New York. Available at: https://wearesocial.com/blog/2018/01/ global-digital-report-2018

Weiner B., Amick H. and Lee S. 2008. Conceptualization and measurement of organizational readiness for change, Medical Care Research and Review, 65(4), 379-436. Available at: https://journals.sagepub.com/doi/pdf/1 $\underline{0.1177 / 1077558708317802}$

Zazueta S. and Vergot P. 2003. Use of handheld computers in agricultural extension programs, Proceedings of EFITA2003, Debrecen-Budapest, Hungary. Available at: http://www.efita.net/apps/accesbase/bi ndocload.asp? $d=5268 \& \mathrm{t}=0$ \&identobj $=$ MsPqKSYE\&uid $=57305290 \&$ sid $=57 \& i$ $\underline{\mathrm{dk}=1}$ 


\title{
A STUDY OF READINESS FOR USING SOCIAL MEDIA IN AGRICULTURAL EXTENSION IN ASSIUT GOVERNORATE
}

\author{
Abdel-Ghany M.M.M. \\ Rural Sociology \& Agric. Extension Dept., Fac. of Agric., Assiut Univ., Assiut, Egypt \\ *Corresponding author: abdelghany18@aun.edu.eg
}

Received 26 May, 2019

Accepted 19 September, 2019

\begin{abstract}
This research attempts generally to discuss the readiness for using social media in agricultural extension in Assiut governorate, and it endeavors particularly to reach the following aims: (1) Measuring readiness of the extension organization in Assiut governorate to start providing agricultural extension services using social media from the viewpoint of extension employees; (2) Exploring the willingness of farmers in some villages in Assiut governorate to obtain agricultural extension services using social media, and to identify the most significant determinants of the willingness to use social media; (3) Knowing about the respondents' views about the advantages, disadvantages and suggestions of using social media in agricultural extension. The study was conducted on two groups of respondents who use at least one of social media tools; the first was comprised of 86 extension employees in Assiut governorate, and the second was a sample of 120 farmers selected from four villages in Assiut governorate. Data were collected using questionnaire form during the
\end{abstract}

period from November to December 2018. Frequencies, percentages, arithmetic mean, and stepwise multiple regression analysis were used for data presentation and analysis. The results indicated a decrease in the extension organization's readiness for using social media from the viewpoint of extension employees, while farmers have a high willingness to use social media to obtain extension services. Therefore, it is necessary to use the recommendations of improving the extension organization's reediness to use social media, in order to exploit the high willingness of farmers, and start using social media to provide extension services in Assiut governorate through implementing an initial initiative through farmers who use social media, and then the initiative can be expanded to include non-users through their family members who are using social media, taking into account the respondents' suggestions for the successful use of social media in the provision of agricultural extension services.

Keywords: Readiness, Social Media, Agricultural Extension, Assiut Governorate 